

\title{
Modeling the integrated mine-to-client supply chain: A survey
}

\author{
João Marcelo L. G. Leite ${ }^{\mathrm{a}}$, Edilson F. Arruda $^{\mathrm{a}}{ }^{*}$, Laura Bahiense $^{\mathrm{b}}$ and Lino G. Marujo ${ }^{\mathrm{a}}$ \\ ${ }^{a}$ Industrial Engineering Program, Alberto Luiz Coimbra Institute - Graduate School and Research in \\ Engineering, Federal University of Rio de Janeiro, Rio de Janeiro, Brazil \\ ${ }^{b}$ Systems Engineer and Computer Science Program, Alberto Luiz Coimbra Institute - Graduate School and \\ Research in Engineering, Federal University of Rio de Janeiro, Rio de Janeiro, Brazil
}

\begin{abstract}
Mining is an important economic activity and a highly complex industry. As such, it demands a complex supply chain to connect mines to clients, often involving railways, ports and long-distance maritime shipping. State-of-the-art optimization tools are an invaluable asset to help manage such a complex environment, which makes mining industry a very fertile ground for operational research applications. This paper aims to present a bibliographical review of published works involving operational research applications in the mining industry. We start by mapping applications within each isolated link of the chain. Then, we make inroads into the researches involving and connecting multiple links of the mining chain. Finally, we present summaries of our finding and pinpoint some directions for research opportunities in the mining industry.
\end{abstract}

Keywords: Mining Industry; Supply Chain; Operational Research; Optimization; Bibliographic Review

\section{Introduction}

Mining is an essential economic activity, which amassed a global revenue of 496 billion U.S. dollars in 2016 [1]. In many countries, mining is responsible for a large share of the Gross Domestic Product (GDP); in particular, mining industry accounts for around 5\% of the Brazilian GDP and was responsible for more than a third of the Brazilian trade balance in 2016 [2].

As it involves a supply chain with multiple interlinked activities, mining industry features a rich sample of potential operational research (OR) applications. These applications become even more appealing given the significant amount of investment that the industry demands. It is usual to divide the different OR problems according to the stages they happen within the mining supply chain. In this work, we will adopt the following classification:

Mine: involves OR problems in open-pit and underground mines, such as: mine layout and design; production and scheduling; and operational equipment allocation.

Railway: accounts for railway scheduling decisions;

Port: covers stockpiling, conveyor routing and ship loading problems in the port area;

Maritime Shipping: includes scheduling and routing of cargo ships;

Supply Chain: applications that aggregate more than one stage in the logistics supply chain. Some examples are planning and scheduling, blending and capacity expansion problems.

A graphical illustration of the proposed classification is depicted in Figure 1. There, the numbers in parenthesis indicate the number of surveyed papers which were analyzed in each category.

The vast literature in the area motivated a number of bibliographical reviews on the application

${ }^{*}$ Corresponding author. Email: efarruda@po.coppe.ufrj.br 


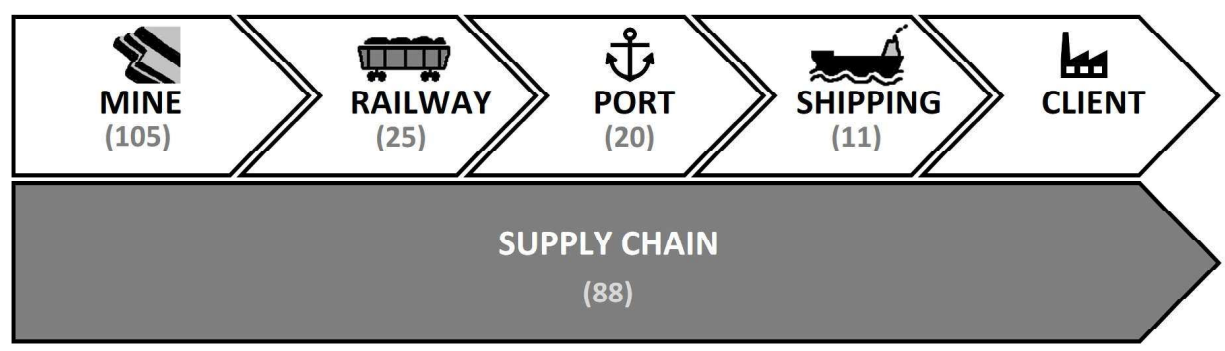

Figure 1. Mining Supply Chain Classification

of OR techniques to mining problems [3-6]. In their excellent work, Caccetta [4] identified multiple optimization applications in the mining industry. As it focused on mine optimization and transport and logistics network design, the work lacked an extensive covering of port and maritime shipping problems. The comprehensive survey in [6] covered OR problems in almost every stage of the mining industry supply chain, with the exception of maritime shipping. However, these stages were examined only individually, with no broader categorization for problems covering more than one link in the supply chain. Bjørndal et al. [3], on the other hand, concentrated solely on mine and supply chain optimization, not discussing the specifics of railway, port and maritime shipping problems. Finally, a number of studies were mostly concerned with mine optimization [e.g., 7-10].

This paper aims to present a bibliographical review of OR applications related to all stages in the supply chain of the mining industry. In contrast to other existing bibliographical reviews (BR), this work does not focus on just one link of the mining supply chain. Nor does it simply cover each link individually and separately. Instead, it covers the literature within each of the four traditional stages (mine, railway, port and shipping), but with a special interest in problems that involve multiple links. After an extensive investigation regarding these papers, a fifth category was created for them. Another distinguishing contribution of this paper is a deep investigation within the methodologies, thus providing a better characterization of objective functions and model constraints. In addition, the paper discusses how current issues such as environmental concerns and new technologies have changed mining supply chain OR models.

This work is organized as follows. Section 2 describes the methodology applied. Section 3 covers applications in mine optimization. Railway transport applications are addressed in Section 4. Next, Section 5 deals with port storage applications and Section 6 refers to maritime shipping. Section 7 covers applications involving multiple links of the supply chain. Section 8 summarizes research opportunities and Section 9 concludes the paper.

To improve readability, a list of abbreviations used throughout the text appears in Table 1.

\section{Methodology}

Given the scope and number of articles available about the subject addressed in this study, it was necessary to adopt a methodology to guarantee that the most relevant literature was researched and analyzed. The same methodology was used for each type of model or problem found, varying selection criteria. Table 2 summarizes the work flow executed.

It is noteworthy that nowadays there are dozens of relevant literature databases available. Since it would be impossible to cover them all, six bases recognized for their content in operations research, computer science, engineering and mathematics were selected:

- Google Scholar;

- Microsoft Academic;

- Science Direct; 


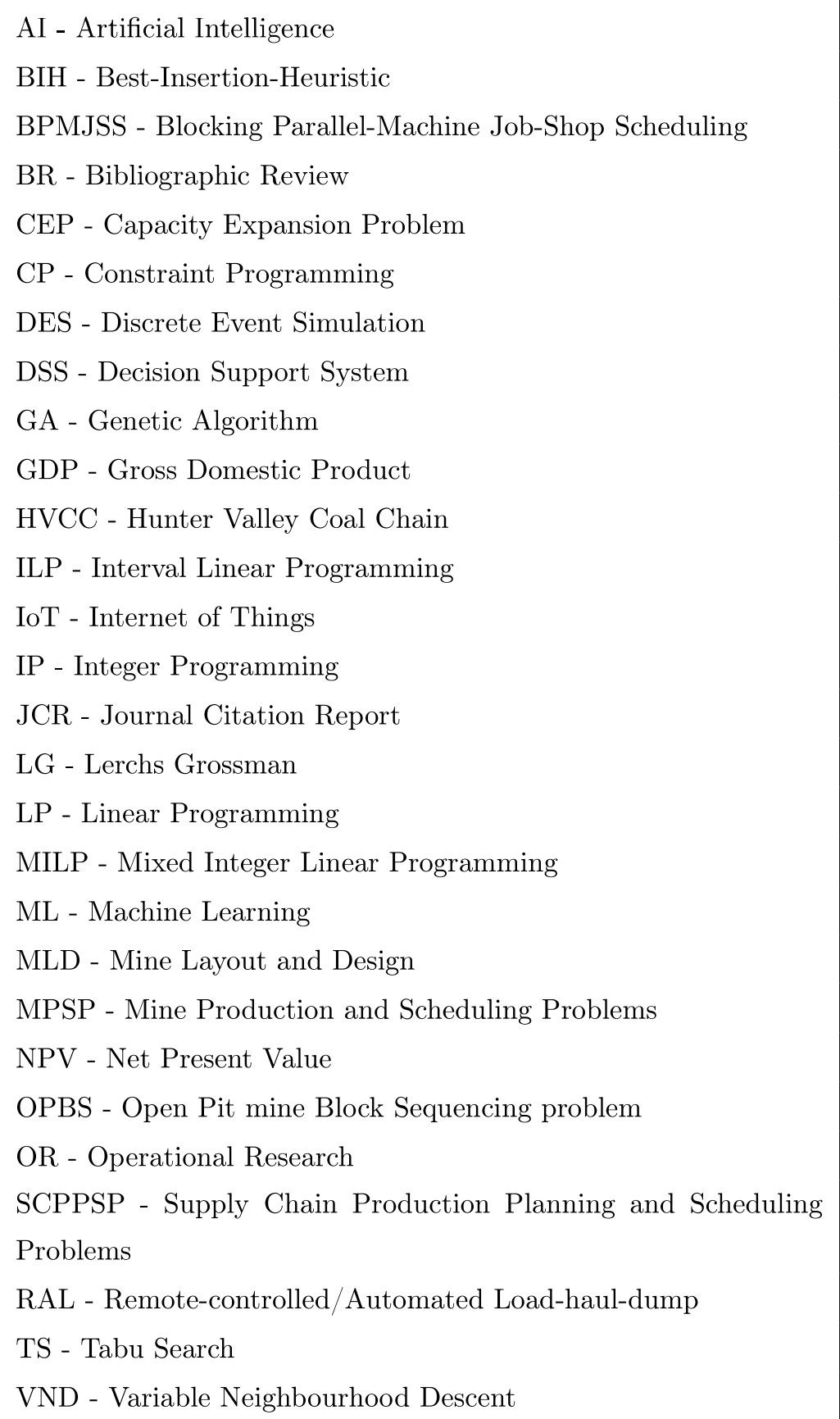

- Scopus;

- SpringerLink;

- Web of Science.

The bibliographic search started using keywords associated to the models and to important topics of mining supply chain problems. The research was expanded with relevant articles that were cited in the researched literature but did not feature in the initial list of references. 
To expand the research beyond the original list of researched papers, we initially evaluated existing Bibliographical Reviews (BR) and the references therein. When necessary to refine the search, the number of citations was included as a selection criterion. For an overview of the selection criteria adopted for each type of model or problem we refer to Table 2.

In some types of problems, it was necessary to adopt a selection criterion to ensure that the most relevant works were studied. Initially, existing bibliographic reviews (BR) were evaluated and used as the first guidelines. The periodic classification carried out by InCites Journal Citation Report (JCR) was used to assist article selection. In addition to BR and periodic evaluation, the number of article citations and its publication year was taken into account. When it was necessary, a minimum citation amount on any of the bases was defined for an article to be selected. The selection criteria adopted for each type of model or problem found are described in Table 2 . To conclude, we reserve the right to include some papers deemed relevant even if they did not meet the selection criteria adopted.

\section{Mine}

One of the most studied OR applications in the mining industry, mine optimization is the subject of a number of scientific works. The literature review in [8] is focused on mine production and proposes a classification in two broad clusters, namely surface mining and underground mining problems. For both categories, the paper classified the problem of determining suitable exploitation layouts in terms operational, tactical and strategic planning. At the strategic level are mine layout and design models, whereas mine production scheduling models belong to the tactical level. Finally, mine operational equipment-allocation models are part of the operational level.

Bjørndal et al. [3] also contributed with a literature review and proposed that the problems should be classified in three groups: strategic mine planning, tactical mine planning and operational mine planning including transportation. For the authors, strategic mine planning includes strategic problems in open pit design and pit boundaries definition. The block sequencing problem is classified as tactical mine planning. Operational mine planning including transportation comprises models designed to find ways for the trucks to meet mine demand. A somewhat distinct classification is proposed by Caccetta [4], who enumerates the following OR applications in mine optimization: pit designs, mine production scheduling, equipment choice and site rehabilitation plan. Kozan and Liu [5], on the other hand, chose to divide mine optimization problems in four categories. The first three groups are similar to those defined in related works: mine design (open-pit mine design and underground mine design), mine production (open-pit ore mining production, underground ore mining production and coal mining production), mine transportation (fleet management, truck haulage and train scheduling). The fourth group is mine evaluation (mining method selection, quality control, financial risk and environmental protection). Finally, in [6] the authors opted for a broader categorization, involving only two types of OR problems: open-pit and underground mine scheduling and mine load and haulage equipment allocation. It is worth mentioning, however, that the authors include the ultimate pit design problem in the first category.

We will make use of the classification below, which is adopted by most authors:

(1) layout and design models;

(2) production and scheduling problems (MPSP);

(3) operational equipment allocation models.

Table 3 features a list of surveyed papers, selected according to the methodology in Section 2 and Table 2, and classified according the adopted rule. The category with the largest number of surveyed articles is production and scheduling problems. A relatively smaller body of literature deals with operational equipment allocation models.

It is very common in the logistics literature to classify decision problems according their time 


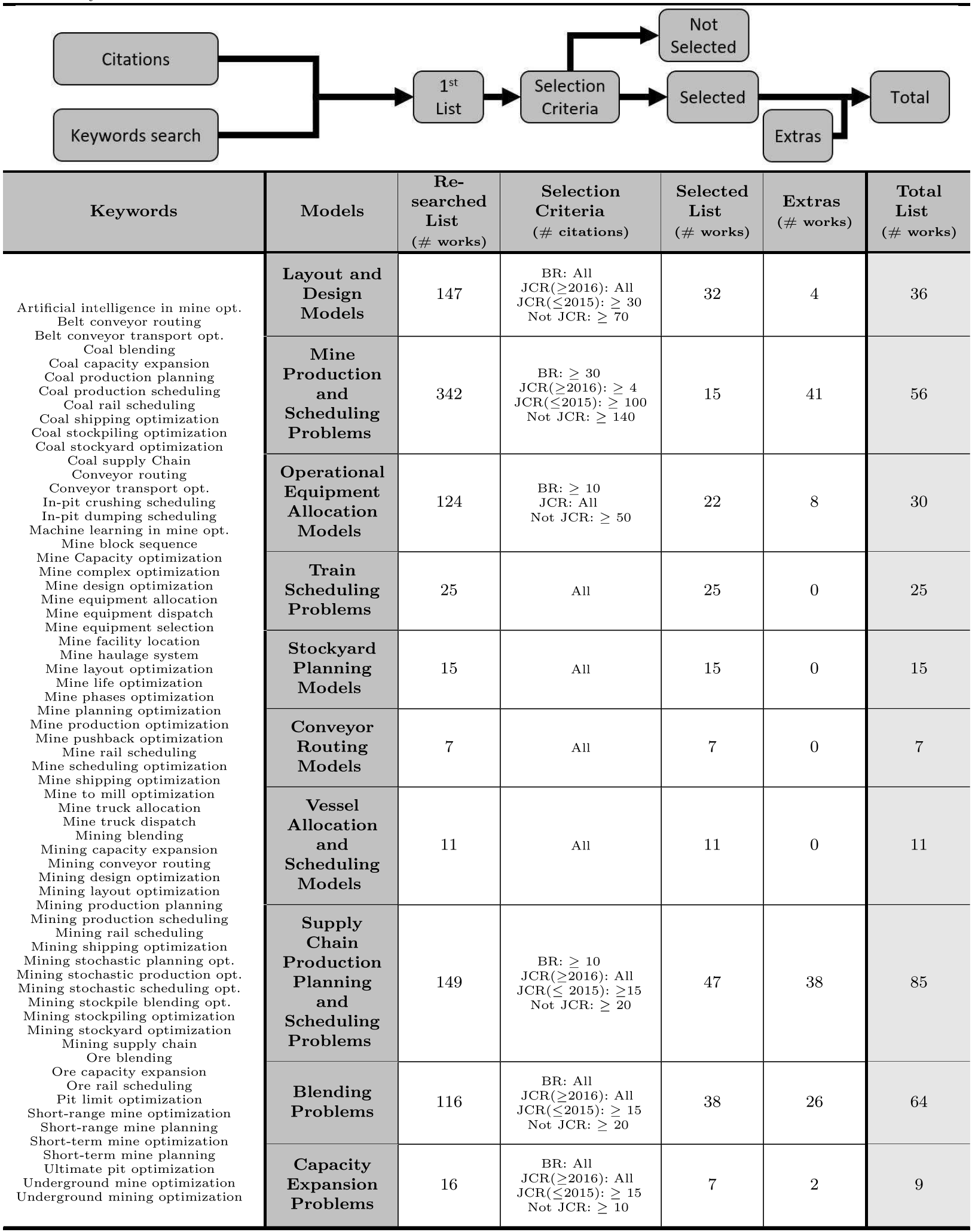

horizon. As an example, [108] divided the supply chain decision phases into three groups:

- Strategic: when a company designs their supply chain structure for the next several years; 


\begin{tabular}{|c|c|c|c|c|}
\hline & $\begin{array}{c}\text { Bibliographic } \\
\text { Review }\end{array}$ & Deterministic & Stochastic & \# Articles \\
\hline $\begin{array}{c}\text { Layout and } \\
\text { Design Models }\end{array}$ & {$[3-6 ; 8 ; 11-15]$} & [16-32] & [33-41] & 36 \\
\hline $\begin{array}{l}\text { Production and } \\
\text { Scheduling } \\
\text { Problems }\end{array}$ & $\begin{array}{c}{[3-6 ; 8-} \\
10 ; 14 ; 15 ; 42]\end{array}$ & [43-69] & [70-88] & 56 \\
\hline $\begin{array}{l}\text { Operational } \\
\text { Equipment } \\
\text { Allocation } \\
\text { Models }\end{array}$ & $\begin{array}{c}{[3 ; 5 ; 6 ; 8 ; 15 ; 42} \\
89-91]\end{array}$ & {$[7 ; 60 ; 61 ; 92-101]$} & {$[70 ; 78 ; 102-107]$} & 30 \\
\hline
\end{tabular}

- Planning: considering that the configuration of the supply chain is fixed, a company selects its strategy for a short period that may vary from a quarter to a year;

- Operational: a company makes decisions regarding customers' orders in a weekly or daily time horizon.

Some authors use the same group classification for mining supply chain problems. Newman et al. [8] classify "Ultimate Pit Limit Design and Mine Layout Models" as strategic, "Block-Sequencing Models" as tactical and "Equipment-Allocation Models" can be either tactical or operational, depending on the time horizon. Pimentel et al. [6] made a similar classification. For the authors, the "Strategic Mine Planning" problem is strategic. "Ultimate Pit Limit", "Production Scheduling" and "Storage and Blending" are tactical problems. Finally, "Mine equipment allocation", "Storage and Blending" and "Train Loading" problems are operational.

Another group of authors adopt a different classification, comprised of short-term and longterm problems. Long-term models usually maximize the net present value (NPV) within the mine life span. Short-term models can optimize equipment utilization or minimize operational costs, following ore grade bounds or volume targets defined previously during the long-term planning [42; 92]. Usually, operational equipment allocation models are associated to short-term planning and production and scheduling problems to long-term planning.

The remainder of this section features a detailed review of mine optimization models. Section 3.1 discusses mine layout and design models; Section 3.2 addresses mine production and scheduling models; and mine operational equipment allocation models are discussed in Section 3.3. In all these sections, the researched papers are classified in "Open-pit" or "Underground" mining and their characteristics and differences are explored.

\subsection{Mine Layout and Design Models}

Mine layout and design (MLD) models search for the most profitable contour to exploit the ore body. That means planning the shape of the mine up to the end of its life, which is referred to as the ultimate pit limit. MLD is important because it determines mine feasibility by prescribing the sequence of exploration stages. 


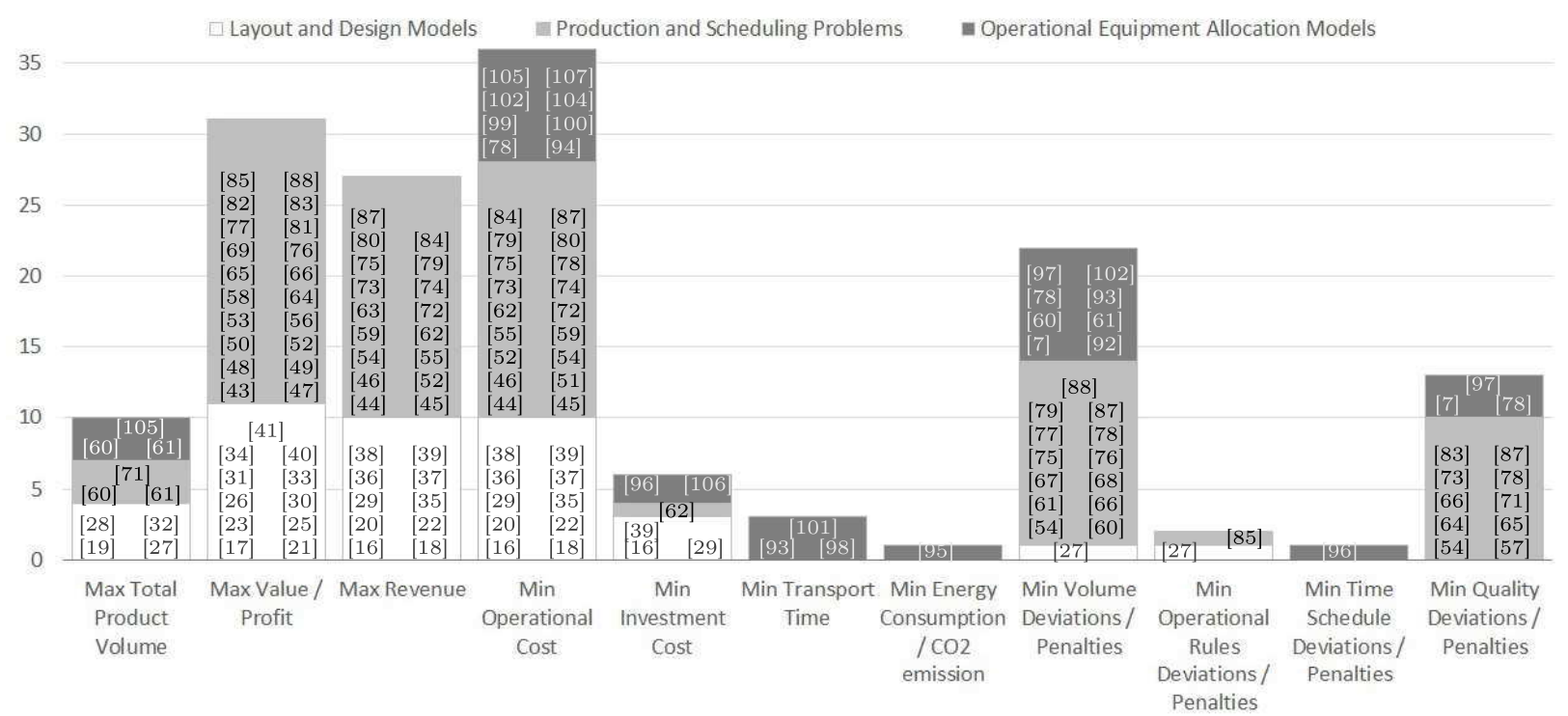

(a) Objective Functions

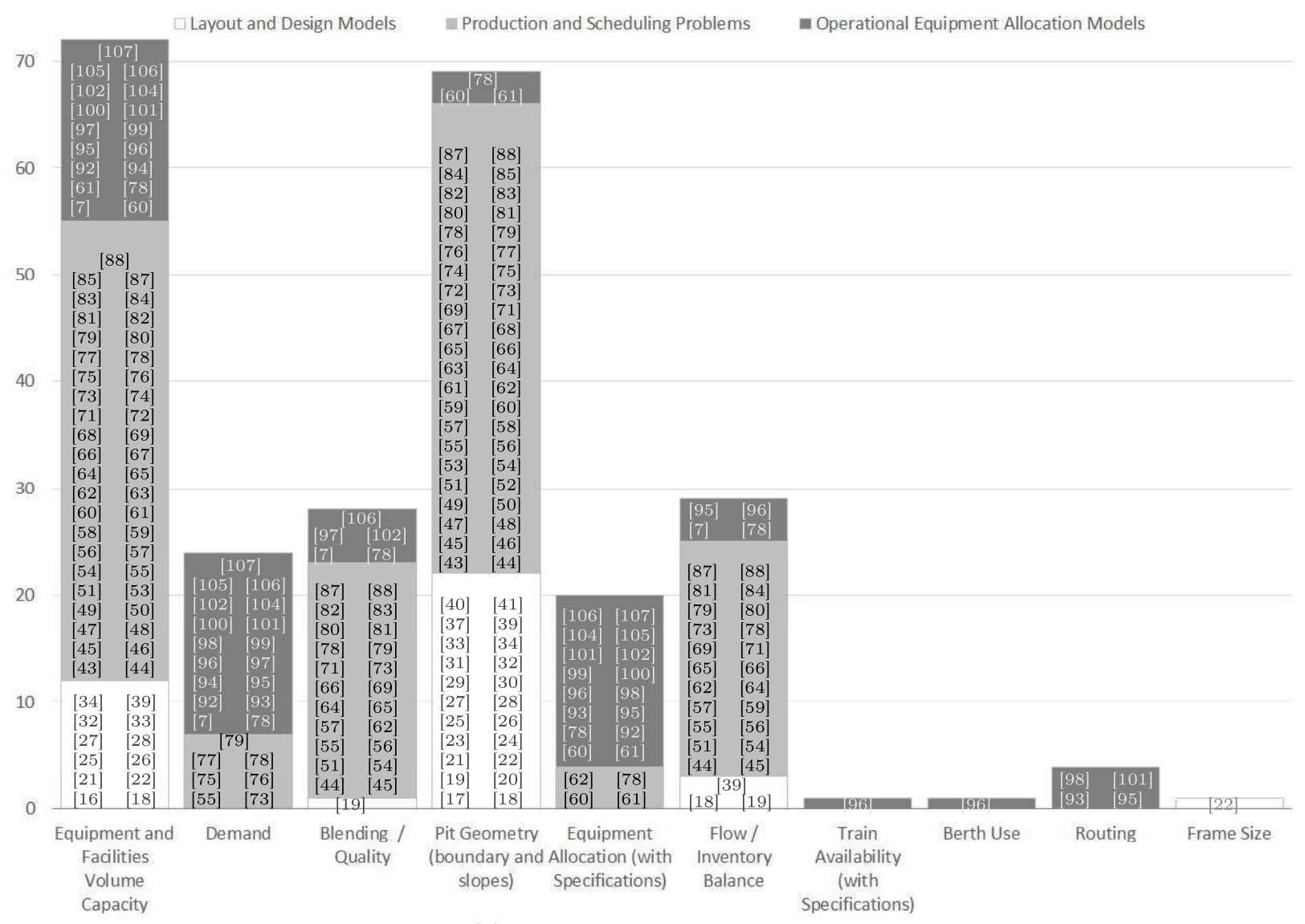

(b) Constraints

Figure 2. Mine Articles

\subsubsection{Open-pit Mining}

MLD models arose in the literature in the 1960's, focusing on Open-Pit Mining. Some interesting bibliographic reviews regarding these models are $[3 ; 4 ; 6 ; 8 ; 12 ; 109]$. According to Newman et al. [8], 
the standard approach of the pit design problem 'uses a discretized orebody model, i.e., the block model'. They argue that there are two principal classical methods to determine the shape of a surface mine: a) the floating cone method, developed by Laurich and Kennedy [110] and b) the integer program model presented by Lerchs and Grossman [20]. An MLD problem is a network model that can be solved using a maximum flow algorithm [3], such as that proposed by Lerchs and Grossman [20], still used nowadays [5]. Other mine design optimization models include Seymour's Parametrized Pit Limit Algorithm, Network Flow Approaches, Dagdelen-Johnson Lagrangian Parametrization, IP Formulations and the Fundamental Tree Algorithm. For more details on these approaches we refer to [12] and references therein.

Lerchs and Grossman [20] proposed two deterministic methods to solve the problem: a simple dynamic programming algorithm for the two-dimensional pit and a graph algorithm for the threedimensional pit. Because it generally finds the optimal solution rather rapidly, this algorithm is implemented in many specialized commercial software packages and can be viewed as a maximum flow problem [e.g., 111]. Some authors strove to propose improvements Lerchs and Grossman's model [20]. Underwood and Tolwinski [23] developed a duality based network flow algorithm and Hochbaum and Chen [17] suggested an adapted maximum flow push-relabel algorithm. Both authors compared their results to the LG Algorithm and claimed to have found better results.

Objective functions and constraints used in mine layout and design (MLD) models are shown in Figures 2 a) and 2 b), respectively.

Recent deterministic approaches often focus on different aspects of the open-pit design problem. A cut-off grade optimization model which considers the escalation of metal price and operating costs was studied in [25; 26]. In contrast, Jélvez et al. [27] proposed a model for automatic selection of pushbacks which made use of MILP techniques. Rahmanpour and Osanloo [21] developed a decision support system (DSS) that considers sustainability indicators. Sari and Kumral [22] developed a MILP model to solve the dig-limits problem where ore and waste clusters correspond to mine excavator movements. Ahmadi and Shahabi [16] applied a genetic algorithm to determine the optimal cutoff grade, maximizing the net present value. Ahmadi and Bazzazi [28] tested two different metaheuristic optimization algorithms (Particle Swarm Optimization and Imperialist Competitive Algorithm) to determine the optimal cutoff grade in mine No. 1 Golgohar. In their research, Imperialist Competitive Algorithm presented a higher accuracy. Klingman and Phillips [19] presented an integer programming model to support optimal mining strategic decisions for a phosphate productor with blending constraints. Osanloo and Ataei [29] focused on multiple material deposits. They proposed that for all metals, an equivalent grade of main metal should be determined and used. Then, traditional techniques can be applied and the problem can be solved as if there was only one variable.

As for stochastic models, they seem to have gained momentum in the 1990's. Table 3 illustrates the division in the literature between deterministic and stochastic approaches. Dowd [38] used geostatistical simulation to develop sensitivity and risk analyses involving reserve estimation and open-pit planning, considering uncertainty in the ore reserve. In $[35 ; 36]$ one can find a model that accounts for grade, tonnage and geology uncertainty. The authors suggested two new implementations of conditional simulation: the generalized sequential Gaussian simulation and direct block simulation. According to simulated stochastic parameters (such as gold price, copper price, capital cost and plant utilization), [39] used four categories of options that can be incorporated dynamically into their model: mine options, pre-processing stockpile options, processing plant options and capacity constraint options. Asad and Dimitrakopoulos [33] developed a graph representation solved by means of a parametric maximum flow algorithm with Lagragnian relaxation that employed the subgradient method. They consider uncertainties in the mineral deposit and in commodity prices and address such uncertainties by simulating multiple realizations. [37] suggested the upside/downside approach to the mine design problem, taking into account orebody uncertainty. They start with orebody simulation data, then use the LG algorithm with the heuristic Milawa mine production scheduler to solve each simulated orebody. Finally, they implement risk analysis for all solutions. 
[34] developed a minimum cut network flow algorithm for open-pit mine design. The model also uses a smoothing splines algorithm with sequential Gaussian simulation to consider commodity price or market uncertainty. Recently, Farmer and Dimitrakopoulos [40] proposed a schedule-based push-back design method with multiple ore-body simulations to optimize pit design and pit limit problems.

\subsubsection{Underground Mining}

Another line of research that emerged most recently was underground mine design. Not as studied as open-pit models, underground mine limits models are different from open-pit mine problems. According Bjørndal et al. [3], 'underground mine design is more complicated, not only because there are more operational constraints to consider but also because there is no single, generic design model that is applicable to all underground mines'. Pimentel et al. [6] argue that underground operations are more challenging from a computational standpoint.

Although fairly recent, underground mine design is the subject of intense research, as well as bibliographical reviews $[11 ; 13]$. In [11; 13], the authors classify the existing algorithms in exact and heuristic. They enumerate the following exact algorithms: a) dynamic programming, b) downstream geostatistical approach, and c) branch and bound for integer programming. They also listed the following heuristic algorithms: a) octree division, b) floating stope, c) multiple pass floating stope, d) maximum value neighbourhood, e) Topal and Sens heuristics, f) network flow, g) Sandanayake's heuristic. Both reviews present comparisons between these different algorithms. Topal and Sens [30] proposed an algorithm that can find the true optimal solution for the 3D stope layout problem. Sandanayake's heuristic incorporates stope size variation and outperformed the Maximum Value Neighbourhood algorithm in a realistic ore body model test [31]. Considering grade uncertainty, Grieco and Dimitrakopoulos [32] formulated a stochastic MILP with risk analysis and applied it to Kidd Creek Mine, Canada.

An option found in the literature is to consider simultaneously open-pit and underground phases [18; 24]. King et al. [18] used a MILP with an adhoc branch-and-bound strategy for solving linear programming (LP) relaxations and a rounding heuristic to convert the LP relaxation to MILP solutions. The method proposed in [24], on the other hand, starts by optimizing the design of an open-pit mine, framed as a maximum graph closure problem. Then, it introduces non-trivial strongly connected sub-graphs (NSCSs) to deal with the transition to the underground phase.

\subsection{Mine Production Scheduling Problems (MPSP)}

Another application of OR in the mining industry, which has led to a number of published works, is to help mine production scheduling decisions. This application gives rise to mine production scheduling problems (MPSP), which appear in the literature under various names:

- Long-term production planning (LTPP): [9];

- Long-term (open pit) mine planing: [43; 75];

- Mine production scheduling problems (MPSP): [4; 52; 76; 77];

- (Multi-period) open pit (mine) production scheduling (problem): [44; 45; 53; 57; 72];

- Open pit mine block sequencing problem (OPBS): [50];

- Resource-constraint pit optimization (R-C Pit): [43; 48; 49].

Since the aforementioned models are designed to define mine production schedule over time, it is no surprise that they are all multi-period. There also seems to exist a consensus on the modeling technique. To solve MPSP, authors divide the mines into blocks and propose models to decide if and when each block should be mined. For some bibliographic reviews in this area we refer to [3-6; 8-10]. These papers cover several aspects of the problem and help us to attain a better understanding of 
MPSP definition and characteristics.

MPSP often makes use of a discretized orebody model known as block model [8]. Such a model aims to prescribe an order for the blocks to be removed [4; 8]. Mine production scheduling problems can be distinguished from the mine layout and design models of Section 3.1 in a number of ways. The main difference is that, while the latter focuses on selecting blocks to be removed, the former is concerned with when the blocks should be removed [8]. According to Bjørndal et al. [3] the block sequencing problem can be classified either as strategic or as tactical, depending on the model complexity. Generally, the objective is to maximize the total discounted profit, considering both selling prices and operational costs. The set of constraints include, for instance, mine extraction sequence, slope safety rules, production and stockpile capacities and product quality $[4 ; 6 ; 8]$

For the same reasons explained in Section 3.1, MPSP have different characteristics when we compare open-pit and underground mining. For a literature review on system simulation studies in underground and open-pit mines, we refer to [10].

\subsubsection{Open-pit Mining}

In a related review about open-pit mining, Kozan and Liu [5] classified MPSP models in two categories, according to the commercialized product: 'ore mining production' and 'coal mining production'. They argue that ore mining and coal mining have distinct requirements, since the former is found in hard-rock whereas the latter is encountered in sedimentary rocks. For a classification of MPSP models into deterministic and uncertainty-based approaches, we refer to [9]. We will adopt this classification later in this work.

Generally, the decision maker wishes to maximize the net present value (NPV) of the overall mine production throughout its lifetime. There are, however, distinct objectives that may be pursued. Figure 2a) summarizes objective functions found in the literature. The numbers within the histogram refer to the mapped articles.

In the optimization process, however, some constraints must be enforced. We find in the literature of Mine Production Scheduling Problems mentions to the following constraints:

- Equipment and Facilities Volume Capacity: Solution must obey production (mining, milling and refining), machinery and storage capacities at all times;

- Demand: demand should be met at all periods. Depending on the stage of the supply chain, this constraint may refer either to the demand of the final client or that of the next link (player) in the logistics supply chain;

- Blending / Quality: The final product must meet the specifications for quality and purity. These constraints are also known as the blending problem. We will deepen the study on this theme later (Section 7.2);

- Pit Geometry (boundary and slopes): It is impossible to mine a rock if you do not have access to it. For example, in an open-mine it is necessary to start mining in the surface in order to be able to access the deepest areas following a mining extraction sequence;

Almost all models have Pit Geometry (boundary and slopes) and Equipments and Facilities Volume Capacity constraints. Figure $2 \mathrm{~b}$ ) depicts the constraints found in the literature. It is interesting to notice that 13 articles also addressed the blending problem. Only 7 articles included demand constraints, which means that most of them assume it is always possible to deliver everything that is produced.

Some models go deeper and consider the various processes that occur inside the mine. First of all, when a block is extracted, if its ore grade is low, it does not follow the mining process. Instead, it is send to a waste dump $[51 ; 55 ; 60 ; 61]$. If its ore grade is acceptable, it follows to in-pit crushers $[62 ; 73 ; 102]$ and afterwards, it goes to milling facilities $[6 ; 79 ; 80]$ to adjust its size and be prepared to be sent to the processing plants. This whole process is known as Mine-to-Mill and increases the model complexity. 
Naturally, some parameters may change as the project evolves. In fact, some of them may even not be precisely known from the beginning. In other words, there may be uncertainty in the model parameters. However, not all models address parameter uncertainty. Most papers employ deterministic approaches that assume fixed and completely known parameter values during the whole execution time of the project. Nonetheless, there is a significant portion of stochastic approaches in the literature, as illustrated in Table 3.

The early deterministic formulations used LP models to solve MPSP. Johnson [53] formulated a linear model to solve the multi-period open pit mine production scheduling problem by means of a block formulation. Later on, some authors started to use integer or MILP models. Gershon [52] presented four models to solve MPSP; three of them employ block-discretization with LP, integer programming and MILP, whereas the remaining model applies column-discretization with LP. Fytas et al. [62] also describe a computer package using LP capable of optimizing short-term mine production and scheduling.

An important issue for integer programming or MILP MPSP models is that the number of variables and constraints increases very rapidly in real-world applications, and that may render the problem computationally intractable for moderately large problems. To circumvent this issue, some authors propose simplified versions of the problem and/or apply heuristic algorithms [e.g., $4 ; 44 ; 45]$.

Making use of a simplified model, Weintraub et al. [59] proposed an aggregation method based on clustering analysis to run a global model for all mines of CODELCO, the Chilean state copper mine. Comparisons between simplified approaches and traditional MILP models were proposed in [44; 45], in the light of an iron ore mine case study. Their formulation combines mining blocks into larger units called mining-cuts. Under a distinct approach, Pourrahimian et al. [56] propose a multi-step method for long-term MPSP, comprised of three levels: a) aggregated drawpoints, b) drawpoint level, c) drawpoint-and-slice level. Each step involves the solution of a MILP problem, and the overall objective is to maximize the net present value (NPV).

Often designed to find good solutions for complicated problems in reasonable time, heuristic algorithms are found rather frequently in MPSP applications. Busnach et al. [46] developed an integer programming model solved by means of a heuristic algorithm to maximize NPV for a phosphate mining plant in Israel. A three-step methodology was proposed in [48; 49] which: 1) applies the critical multiplier algorithm to solve the LP relaxation, 2) rounds the fractional solution with a rounding heuristic, 3) uses a local-search heuristic to find better solutions in the vicinity. In a distinct approach, Cullenbine et al. [50] proposed a 'sliding time window heuristic' to solve an integer programming formulation in reasonable time. In the authors own words, the heuristic utilizes '(i) fixed variables in early time periods, (ii) an exact submodel defined over a "window" of middle time periods, and (iii) a relaxed submodel in later time periods'. Finally, Caccetta and Hill [47] introduced a branch-and-cut algorithm to find provably good solutions for practical sized problems.

Even though IP and MILP seem to be the main modeling techniques for MPSP problems, other techniques have also been applied in the literature. For example, Tolwinski and Underwood [58] developed an algorithm that combines dynamic programming and heuristics to solve MPSP instances in reduced time. Also, a genetic algorithm was utilized in [57] to reach the product quality specification in a bauxite deposit over two years. The focus was on controlling percentages of $\mathrm{Al}_{2} \mathrm{O}_{3}$ and $\mathrm{SiO}_{2}$ during the mine production process. The paper evaluated five grade control plans.

The treatment of uncertainty is rather recent in MPSP models. Ore content variability seems to be an important issue, since the purity content of the blocks may not be known a priori. Many authors address uncertainty by means of scenario generation techniques. The rationale is to find the alternative that performs best over all the generated scenarios, often in terms of expected value. We refer to [81] for an application on ore body models. There, the authors first solve a deterministic version of the problem and then apply scenario generation to evaluate the probability that a given block is mined at any given time period. The simulation results are then utilized 
to propose adjustments in the original solution and improve performance. Halatchev [74] applied Monte Carlo simulation to simulate ore-grade variance. Gilani and Sattarvand [82] used two different strategies (single predefined probability value and multiple probability values) to improve the initial solutions created by deterministic ACO procedure. [80] features a heuristic approach to solve the MPSP considering multiple scenarios. The authors claim that their treatment of uncertainty was able to increase the NPV by $30 \%$. Finally, Mai et al. [83] proposed a framework to reduce the computational time. First, the authors utilized the TopCone algorithm to cluster simulated orebody models. After that, they solved a stochastic model with NPV maximization and production risk minimization.

Another methodology involves building multi-stage models, which construct a decision tree in which each node is a stage to be solved in the process of maximizing the overall NPV. Boland et al. [72] developed a multistage MILP model which deals with geological uncertainty and new information obtained during the mining process. In the first stage, decisions are made based on the geological information available. In the second stage, information obtained during the process is used in the model. Upon studying a mine production scheduling problem (MPSP) with metal uncertainty, Lamghari et al. [77]; Lamghari and Dimitrakopoulos [84] proposed a two-stage stochastic programming approach and made use of a variable neighbourhood descent (VND) algorithm to find the solution. Also working on a two-stage stochastic model, Lamghari and Dimitrakopoulos [85] proposed a two-phase solution approach based on Rockafelllar and Wets' progressive hedging algorithm. In the first phase, the set of scenarios is partitioned into groups and the sub-problems are solved iteratively. In the second phase, first phase results are used to reduce the original problem complexity, resulting in near-optimal solutions with faster computational time.

Some other tools can also be applied to address uncertainties. A metaheuristic with two diversification strategies solved with Tabu search was proposed in [76] to solve large-scale instances. Mixing NPV and uncertainty cost, Koushavand et al. [75] developed a method to calculate the uncertainty cost in mine production planning. To evaluate variability, the paper proposes simulating different realizations. The technique, which can also use clustering algorithms to reduce the number of variables, was validated through an oil sand deposit in northern Alberta. Inthavongsa et al. [86] used real-options theory to built a dynamics decision-making tool framework with four strategic operating options: deferral, maintain, expand and shutdown. They used discrete-event simulation to evaluate the project. The authors showed that correct options management can increase NPV hedging project risks.

\subsubsection{Underground Mining}

Underground mine planning and scheduling uses the same 3D block-model applied open-pit problems. However, due to a large variety of underground methods and geotechnical space constraints, the problem becomes more involved and complex. There are some interesting bibliographic reviews comparing both problems [e.g., $3 ; 6 ; 14 ; 15]$.

Underground models have gained momentum in the XXI century. In 2001, Carlyle and Eaves [63] built a large mixed-integer programming model to find near optimal solutions for Stillwater Mining Company production scheduling. Almost ten years later, Nehring et al. [64, 65] integrated shortterm and long-term objectives into the same model, combining two objectives: to maximize overall NPV and to minimize short-term grade deviation from target. Their results suggest that combining short-term and long-term goals leads to a more realistic model, which promotes an increased NPV. In 2016, Montiel et al. [87] incorporated geological uncertainty and used a simulated annealing algorithm to optimize a mining complex model.

In order to tackle the complexity underlying underground models, some authors searched for algorithms with reduced computational time. Sarin and West-Hansen [66] developed a general solution methodology based on the Benders' decomposition to optimize a model with quality constraints and with the nodes representing mining sections. Newman and Kuchta [67] developed a MILP program 
to optimize iron production at Kiruna, Sweden. The authors built a heuristic procedure with time aggregation to reduce model complexity. A MILP model was also proposed in Topal [68] which searched for the earliest and latest times for each machine placement. The rationale is to reduce the number of integer variables, and hence the solution time. More recently, Nehring et al. [69] presented a MILP model with a new formulation. The authors used a single variable to represent production start which, in their model, will naturally be followed by drilling, extraction and backfilling. Comparing to classical MILP models, their proposal reduces the computational time while also reaching a near-optimal solution.

\subsection{Mine Equipment Allocation and Selection Models}

According to Newman et al. [8]: 'In addition to determining a production schedule, a related question is determining the resources that enable such a schedule. These are generally separate models in the literature; however, in theory, the decisions are connected. A tactical problem consists of the size and nature of the fleet, which can be determined by artificial and geological mine characteristics and by equipment capabilities. The operational problem of equipment allocation entails scheduling and dispatching strategies; decisions are based on haul route requirements and equipment limitations'. Mine equipment allocation and selection models aim to optimize mining operation taking into account constraints related to the transportation of equipment, see also [6]. This is a very important issue, since material handling utilizes large scale and expensive equipment and accounts for about $50 \%$ of production costs $[99 ; 103]$.

This problem, which is becoming increasingly more studied, was the object of a number of important bibliographic reviews. One of the first is [91], which classified truck dispatching strategies and analyzed different mathematical models, striving to enumerate their strengths and weaknesses. A number of posterior reviews followed $[3 ; 6 ; 8 ; 15 ; 89 ; 91 ; 109]$. A more recent work [90] pointed future research directions in mine equipment allocation: they argue that the new models should explore different types of equipment and researchers should develop complementary techniques to solve problems with uncertainty.

In addition to the objective functions that have already appeared in mine production scheduling problems (see Section 3.2), two new objectives appeared: to minimize transport time and to minimize energy consumption. Figure 2a) illustrates the objective functions in different articles.

There are two new constraints in relation to mine production scheduling problems:

- Equipment Allocation (with Specifications): The number of pieces of equipment needed to complete the task, as well as their specification;

- Routing: Pathway constraints for models with routing;

All models analyzed have demand constraints. One can find routing and blending constraints as well in some models. Figure 2b) illustrates the constraints found in the literature.

Mine equipment allocation and selection models often do not take into account uncertainties in parameters, especially in the early literature. More recently, models that integrate mine equipment allocation and selection, mine production scheduling problems and blending models started to deal with mine volume and quality uncertainty. For a classification of deterministic and stochastic approaches, we refer to Table 3.

\subsubsection{Open-pit Mining}

Open-pit deterministic models, encountered everywhere in the early research, continue to find use nowadays. Soumis et al. [97] develop a model to maximize productivity of trucks and shovels, following a prescribed production plan. Their model has three steps. In the first step, they determine shovel locations using a methodology that combines operator expertise and LP optimization. The 
second step solves a network problem to determine an optimal production plan. In the third step, they allocate each truck to each shovel, according to the optimal strategy defined in step two. Covering a slightly different problem, Naoum and Haidar [94] applied a genetic algorithm to find an optimal equipment usage in terms of the total operation cost. In the field of optimal blending problem, Costa [7] covered optimal blending of mine production, optimal blending of mine production with dynamic equipment allocation and optimal blending of mine production with static equipment allocation. Each problem motivated two models, one based on mathematical programming and one heuristic based approach. One of the most important costs in fleet management is maintenance. These costs were minimized in the MIP model in [99], which considers truck age. The model was tested using data from a Western Australia Mine. Under a different focus, [60; 61] aimed at waste material scheduling instead of ore production. They developed three MILP models with different objective functions: maximize truck productivity, minimize the fleet variation in consecutive years, and a mix of the two former objectives. Focusing on computational time efficiency, Gu et al. [100] proposed a neighborhood search algorithm to find a good solution in an acceptable time to the waste scheduling and equipment allocation problems. Recently, environment has also become a concern in mine equipment allocation and selection models. Naturally, such a concern can be addressed in a number of ways. One possible approach is to optimize energy consumption, as suggested in [95]. That work made use of a MILP formulation with a constructive algorithm and tabu search heuristic to find an optimal truck and shovel allocation in terms of energy consumption. The model was validated on an operating mine in South East Queensland.

Stochastic models are often associated to operational or maintenance variations. Ta et al. [104] considered truckload and cycle time variability. Their model used a chance-constrained stochastic approach with an alternate approach to simplify, which involves solving two sub-models. Ercelebi and Bascetin [105] presented a two stage methodology. In the first step, they used closed queuing network theory to optimize the quantity of trucks. In the second stage, they applied an LP model to determine how the trucks should be dispatched to shovels. [106] also employs queuing theory to formulate a linear approximation to the probability of shovel idleness as a function of the number of trucks. Such an approximation is then inputed to a MILP model whose objective function is to minimize the number of trucks. Following their work in [99], Topal and Ramazan [107] considered maintenance cost uncertainty due to road conditions, age of equipment and many other local operational conditions. The authors used a stochastic integer programming model and compared it to a deterministic approach. Dindarloo et al. [103] worked on a discrete event simulation framework. The model considered uncertainties related to material loading and haulage input variables and was applied to Golegohar iron ore mine, in Iran. Recently, Bakhtavar and Mahmoudi [102] built a two-phase scenario-based robust optimization model considering ore grade control. In the first phase, they considered shovel capacity as uncertain, due to climate conditions, shovel breakdowns and other operational variations. In the second phase, they took into account an uncertainty in the number of available trucks. The model was tested in the Sungun copper complex, Iran.

Other authors considered mine quality uncertainties. Benndorf [70] applied a Generalized Sequential Gaussian Simulation (GSGS) method in a open pit coal operation. They analyzed how calorific value variability impacts the ore supply chain, including extraction, transportation and blending. Matamoros and Dimitrakopoulos [78] developed a stochastic programming model to optimize mine scheduling production and fleet management with blending constraints. The authors simulate ore body metal quantity and quality uncertainty.

\subsubsection{Underground Mining}

There are some works dedicated to equipment allocation in underground mining. In a pioneering work, Vagenas [98] developed a graph procedure to optimize remote-controlled/automated loadhaul-dump (RAL) vehicle operation in an underground mine. In a related approach, Gamache et al. [93] developed a shortest-path algorithm to optimize load-haul-dump vehicles in an underground 
mine. To optimize routing and scheduling vehicles on a haulage network in a underground mine, Beaulieu and Gamache [101] worked on an enumeration algorithm with dynamic programming. More recently, Nehring et al. [92] proposed a new dynamic mathematical model with MILP to optimize short term production scheduling and equipment allocation. The model was tested in a conceptual operation, with five LHD units and three trucks.

\subsection{Literature Summary and Research Opportunities}

It was possible to verify that there are many articles concerning OR applications in mines. The earlier works studied open-pit mines. Due to their complexity, underground mine models developed more recently. Because of that, one can find many research opportunities in this field. While mine production scheduling and mine layout and design problems are specific applications of OR in the mining industry, equipment allocation and selection models are more general and can be found in different business areas. Both mine production scheduling and mine layout and design problems are characterized by the discretization in mine blocks and by the pit geometry constraint.

It is possible to verify that the evaluation of environmental impacts still appears very timidly in the models studied. In a paper on equipment allocation and selection models, the minimization of $\mathrm{CO}_{2}$ emission in the objective function was found. Some authors may argue that environmental concern appears indirectly in minimizing waste costs or minimizing fuel costs, but we believe that there is room for this theme to be addressed more thoroughly in the models. In particular, lifecycle analysis would provide an interesting tool to assess the environmental impacts of the mining industry. Additionally, multi-criteria decision analysis (MCDA) and multi-objetive programming (MOP) models can also be applied, in order to take into account different dimensions of the problem, considering also the standpoint of different stakeholders.

Recently, there are two topics that have become very common in the computer science literature, partly due to the ever increasing data availability: "Machine Learning" (ML) and "Artificial Intelligence" (AI). It is possible to find few attempts to use them in mine optimization problems. They are commonly used for ore body conditional simulation and clustering. Usually, the drilling process does not give information about all mineral deposits. Hence, it is necessary to infer the ore grades of some areas. One of the most used techniques to accomplish that is "conditional simulation", whereby ore body proprieties are simulated based on drilling information [35]. The Sequential Gaussian algorithm is a popular conditional simulation procedure which clusters mine blocks and simulates them simultaneously [32; 36; 83]. Since mine MILP models can rapidly become too large and too time consuming to be solved, some authors focused their researches on clustering techniques to reduce the problem complexity $[45 ; 56]$. Some of the employed clustering techniques used are: Fuzzy C-mean [75], K-means [59] and TopCone algorithm [83].

The most popular application of OR in the mining industry seems to be mine production scheduling problems. For these problems, we have found a larger number of deterministic approaches. Moreover, one can also notice that the papers featuring stochastic models tend to be more recent. Even though mine equipment allocation and selection models do not apply solely for the mining industry, it is an important application in such an industry. There is a fair amount of literature about this topic. Similarly to the other covered applications, most of the literature is concerned with deterministic models. However, one can also notice a trend toward stochastic models in the recent literature.

To sum up, regardless of the specific application, there seems to be a trend toward stochastic approaches in the recent literature related to mine optimization, due to both endogenous and exogenous uncertainties. The former refers mostly to uncertainties in the model parameters, whereas uncertainties in supply and demand are examples of the latter. However, one can also argue that the current stochastic approaches are largely based on simulation and scenario generation. Hence, there is plenty of room different modeling techniques, such as stochastic programming, Markov decision 
processes (MDP), approximate dynamic programming (ADP) and reinforcement learning (RL). In particular, MDP, ADP and RL provide a rather fertile ground for future research, as these models rely on modeling one-step transitions, rather than enumerating scenarios, which may simplify the modeling process.

Finally, it is important to mention the impacts that Internet of Things (IoT) may have on future OR models in the mining industry. IoT will allow access to a greater amount of information and greater traceability for remote equipment. Thus, we believe that models for short-term problems could be better exploited when online information is made available.

\section{Railway Transportation}

Railway is often the preferred means of transportation for the mineral products coming from the interior of the continent [6]. As it happens with mine production and planning, there are plenty of opportunities for using OR in rail transportation.

Some examples of OR applications in railroad transportation are train scheduling, locomotive scheduling, car scheduling and trip planing, railway blocking, and crew scheduling [112]. Some works specifically study the train scheduling problem in the mining industry. The other problems are more specific to railway transportation and we have not found applications in the mining industry. Hence, we decided to focus only on the train scheduling problem.

Table 4 shows the surveyed papers regarding railway transport optimization, selected according to the methodology in Section 2 and Table 2.

Table 4. Classification of Railway Transport Optimization Articles

\begin{tabular}{c|c|c|c|c}
\hline & $\begin{array}{c}\text { Bibliographic } \\
\text { Review }\end{array}$ & Deterministic & Stochastic & \# Articles \\
\hline $\begin{array}{c}\text { Train Scheduling } \\
\text { Problems }\end{array}$ & {$[5 ; 6]$} & {$[96 ; 109 ; 113-129]$} & {$[130-133]$} & 25 \\
\hline
\end{tabular}

\subsection{Train Scheduling Problems}

Train scheduling is concerned with departures, dwell times, crew scheduling, etc. [6; 112]. Naturally, an integration with mining production can increase efficiency [5].

There are four types of constraints that appear in nearly all surveyed papers regarding the train scheduling problems:

- Flow: This constraint ensures that all trains or products move properly, not fading or popping up in inappropriate places;

- Capacity constraints of the facilities and pieces of equipment;

- Demand constraints: to ensure that the demand is met;

- Train Availability: One can only schedule the trains that are available. These are constraints on the number as well as the specification of the trains scheduled.

When it comes to train scheduling problems, there is a wide variation of objective functions which are difficult to categorize. A possible explanation is that authors wish to promote a smooth flow in the railway and there seems to be no standard way of quantifying that. Indeed, one can argue that finding a unifying performance measure is an open problem in the literature. One can notice, however, several types of objectives, which appear categorized in Figure 3a). Figure 3b) illustrates the main constraints found in the researched articles. 


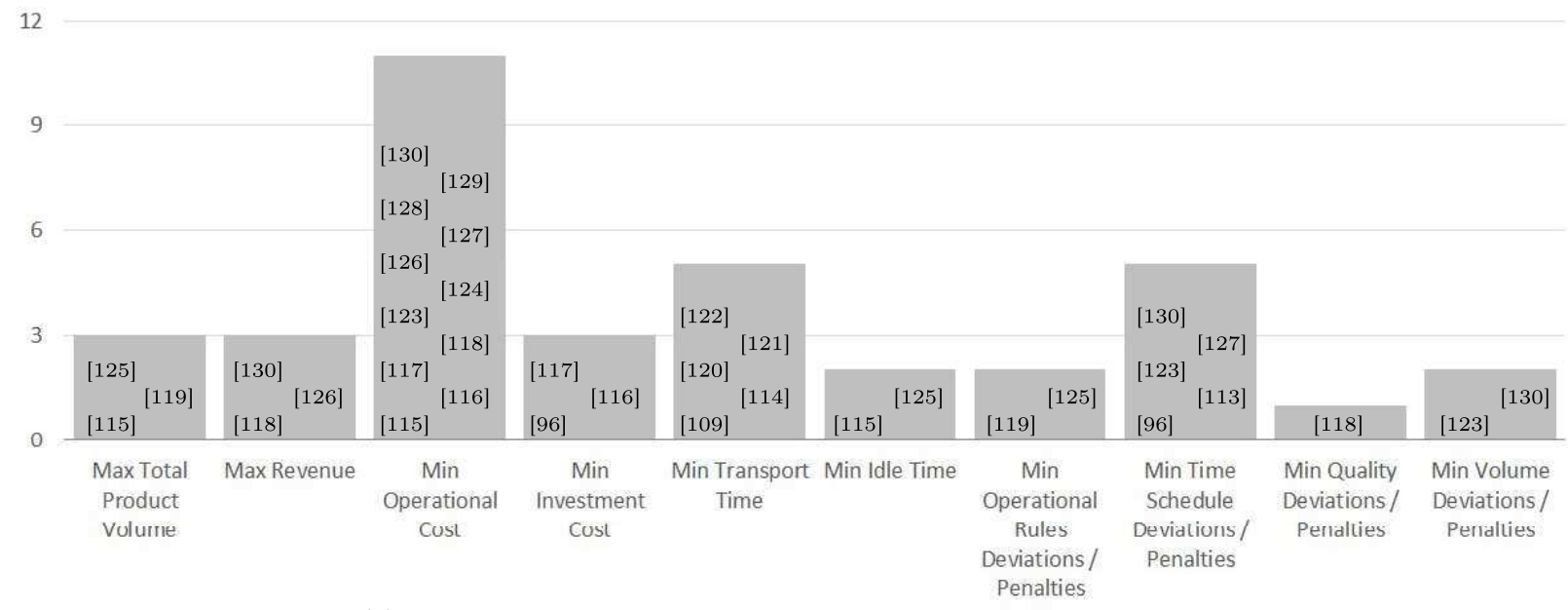

(a) Objective Functions

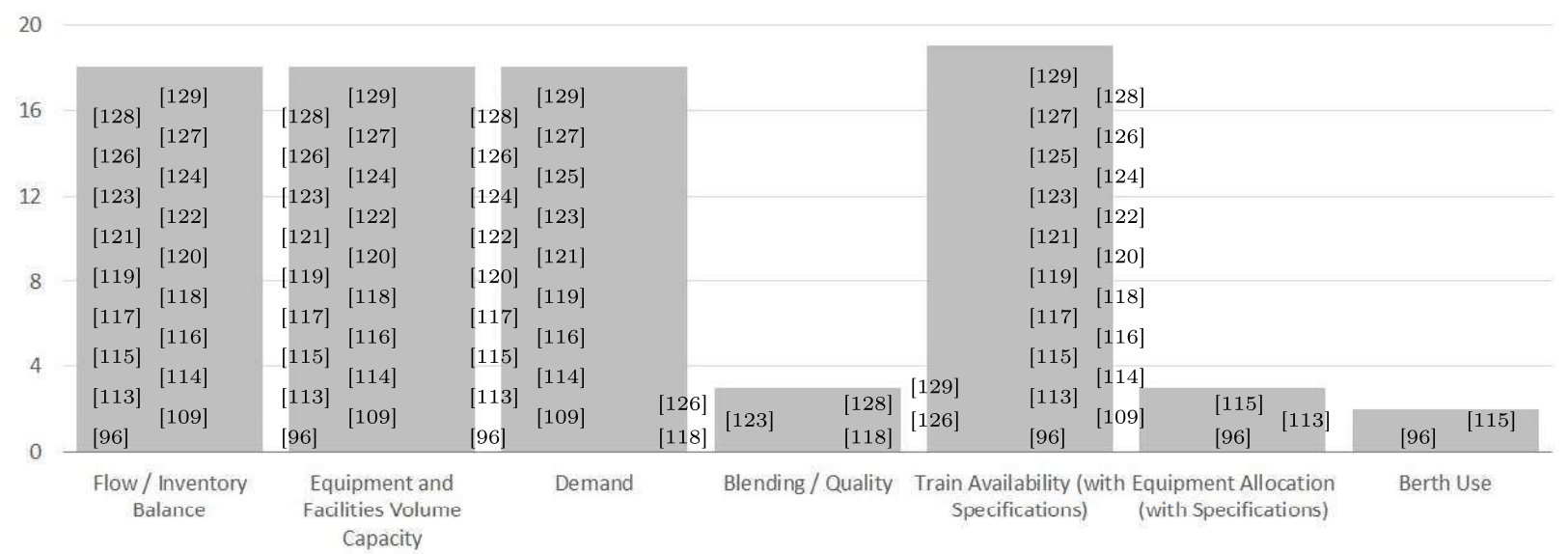

(b) Constraints

Figure 3. Railway Transport Articles

Articles combining train scheduling and mining are rather rare in the literature. Australia and Brazil, countries which are rich in iron ore and have continental dimensions, contributed most to this literature. For some references on Australian railways connected to the mining industry, we refer to $[109 ; 118 ; 120 ; 121 ; 124-126]$. In Brazil, most of the literature is concerned with the Vitória-Minas railway, see for example $[116 ; 117 ; 131 ; 132]$.

As illustrated in Table 4, deterministic models are predominant in train scheduling problems. Salim and Cai [124] developed a genetic algorithm for the train scheduling problem with environmental constraints. One such constraint makes sure that loaded trains do not cross populated areas at certain times of the day. The model was tested in a real problem in the Mt. Newman Mines railway system in Western Australia. In $[114 ; 116 ; 117]$ one finds examples of integer programming models. In [116; 117] one finds optimization models designed to minimize maintenance and fuel consumption costs, under demand, train flow, rail yard, and resource availability constraints. The model was applied to Ferrovia Vitória-Minas, in Brazil. The model in [114], on the other hand, seeks to maximize railway use by accelerating the return of empty wagons. MILP models were employed with the use of heuristic procedures in [109; 119-121; 125]. Liu and Kozan [120, 121] exploited similarities between coal train scheduling and blocking parallel-machine job-shop scheduling (BPMJSS). In [120], they solved the BPMJSS problem using an improved shifting bottleneck procedure (SBP) algorithm without considering blocking conditions. After that, a feasibility satisfaction procedure 
(FSP) algorithm is applied. A posterior work [121] utilized the BPMJSS model with a new threestage hybrid algorithm called the SLEK-BIH-TS, that uses best-insertion-heuristic (BIH) and tabu search (TS). Both studies were validated through a case study in a coal railway system in Australia. Another model based on the same analogy with BPMJSS was presented in [109] to minimize total train travel time following stockpile and ship timetable, which was also applied to a coal railway system in Australia.

Singh et al. [125] used a MILP formulation with a Lagrangian heuristic to solve the scheduling train problem on the HVCC rail network. Their objective function seeks a balance between the quantity of coal delivered to the terminal, the deviation from the preferred dumper-stacker combinations, the total idle time, and the preferred train size for coal pick-up from each of the mines. Resource and volume constraints were applied. Içyüz et al. [119] worked on a specific problem called monthly coal train reservations planning problem (MCTRPP), that occurs in North American railroads. Every month, coal producers ask for train reservation and railway companies strive to meet as much as possible of this demand. The authors utilized MILP to model the problem and suggested two different heuristic methodologies. Non-linear programming models were introduced in [118; 126]. The former paper applied the model with two different heuristics in a Rio Tinto iron ore case study. The latter work also considered the blending problem and validated the model in a supply network in the Pilbara region of Western Australia. Finally, Masoud et al. [122] used a constraint programming (CP) approach to model the train scheduling problem. They developed a new depth-first-search technique and used a real-world coal rail system to test their model.

Two models that considered stochastic parameters made use of discrete simulation. Meireles [132] and de Faria and da Costa Cruz [131] tested their models in the Vitória-Minas railway, in the Southeast of Brazil. A closed loop simulation was proposed in [131]. The model includes: a) general cargo trains (empty and loaded); b) passenger trains; c) ore loading processes; d) ore unloading for external and internal markets. This model enabled the identification of bottlenecks along the railway, as in maintenance and loading-unloading equipment. The results suggested that the number of wagons could be reduced without compromising the service level. Reinhardt et al. [133] applied a different approach, using queuing theory to analyze operational performance in the Powder River Basin railway, in the United States.

\subsection{Literature Summary and Research Opportunities}

Railway transportation presents many opportunities for OR applications. However, since railroads can carry various types of products, only a small portion of the literature is related to the transportation of mining products. In particular, these works are specific to train scheduling problems. There are opportunities to address other railroad OR problems concerning the mining industry.

As well as in mine equipment allocation and selection models, IoT will allow an increasing and online control of railway operation. This will allow the development of short-term models that seek optimal solutions to daily operational problems. In addition, machine learning techniques can be used to predict failures and malfunction based on the online information provided by the railroad and the pieces of equipment.

$\mathrm{CO}_{2}$ consumption is only indirectly addressed in some articles when minimizing fuel cost. No models considering the minimization of $\mathrm{CO}_{2}$ emission were found, despite the ever-increasing importance of such a topic in logistics. The socio-environmental concern arises only in [124], where routing takes into account the impacts of train traffic in cities. Therefore, we believe there is plenty of room for novel models considering not only $\mathrm{CO}_{2}$ emission, but also other environmental concerns. Once again, life cycle analysis (LCA) can be an important tool to assess the overall environmental impact of railway transportation within the mining industry. In addition, Multi-criteria decision analysis (MCDA) and multi-objective (MOP) programming models can be used to evaluate multiple objective functions, as well as the concerns of different stakeholders. 
Due to the complexity of the underlying applications, most of the approaches are deterministic. Hence, there is plenty of room for novel stochastic approaches that can account for the uncertainties in the process such as: track and equipment maintenance, track interruptions, weather conditions, as well as other operational problems. When uncertainty is considered, however, the literature seems to be limited to discrete-event simulation tools. Hence, distinct approaches to address uncertainty are needed. In particular, stochastic optimization (SO), Markov decision processes (MDP), reinforcement learning (RL) and approximate dynamic programming (ADP) provide solid frameworks to modeling and quantifying uncertainty within an optimization environment.

\section{Port}

Port terminals are a very important link in mining supply chain. Often they receive trains carrying products from the mines and store these products until they can be loaded to ships for delivery, sometimes after further processing in the port dependencies. Ports are critical because, as the link between production and delivery, they must not act as bottlenecks. Hence, they should enable a continuous railroad flow by storing the received products in their limited stockyard, in such a way as to avoid ship delays and demurrage penalties. An earlier reference argues that the literature is biased towards simulation due to the complexity of the problem [6].

One can find at least two important problems involving OR in port operations, namely stockyard planning problem and conveyor routing problem. It is possible to find the conveyor routing problem in applications related to underground mines as well. However, such a problem is more common in port operations. So we classified it as Port problem. Table 5 lists all surveyed papers, selected according to the methodology in Section 2 and Table 2, classifying them according to this terminology.

\begin{tabular}{|c|c|c|c|c|}
\hline 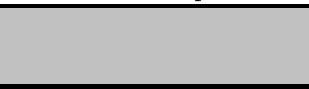 & $\begin{array}{c}\text { Bibliographic } \\
\text { Review }\end{array}$ & Deterministic & Stochastic & $\#$ Articles \\
\hline$\underbrace{\Delta}_{\begin{array}{c}\text { Stockyard } \\
\text { Planning Models }\end{array}}$ & [6] & $\begin{array}{c}{[55 ; 96 ; 113 ; 123 ;} \\
\quad 134-140]\end{array}$ & {$[130 ; 141 ; 142]$} & 15 \\
\hline $\begin{array}{c}\text { Conveyor } \\
\text { Routing Models }\end{array}$ & [6] & [134] & [143-147] & 7 \\
\hline
\end{tabular}

\subsection{Stockyard Planning Models}

In a typical mining port terminal, the product arrives by train from the mines and is transported to the stockyards, where they will stay up to the scheduled ship boarding time. The product is not uniform, having distinct specifications depending on the mine it comes from. Hence, it has to be stored in different areas (pads) to avoid mixing and to guarantee the specifications. Generally, mining port terminals have geographical constraints; moreover, since there is limited capacity, decision makers should avoid keeping products in store for long time periods. Decisions on the storage time are tricky, for it may seem at first glance that keeping products stored well in advance can help guarantee the shipment schedule and thus avoid demurrage penalty. However, since there is limited space in the stockyard, keeping a product too long may, on the other hand, disrupt the flow of products to the port, and hence compromise the shipment schedule. Stockyard planning problems are designed to exploit these trade-offs while striving to find the best pad allocation to 


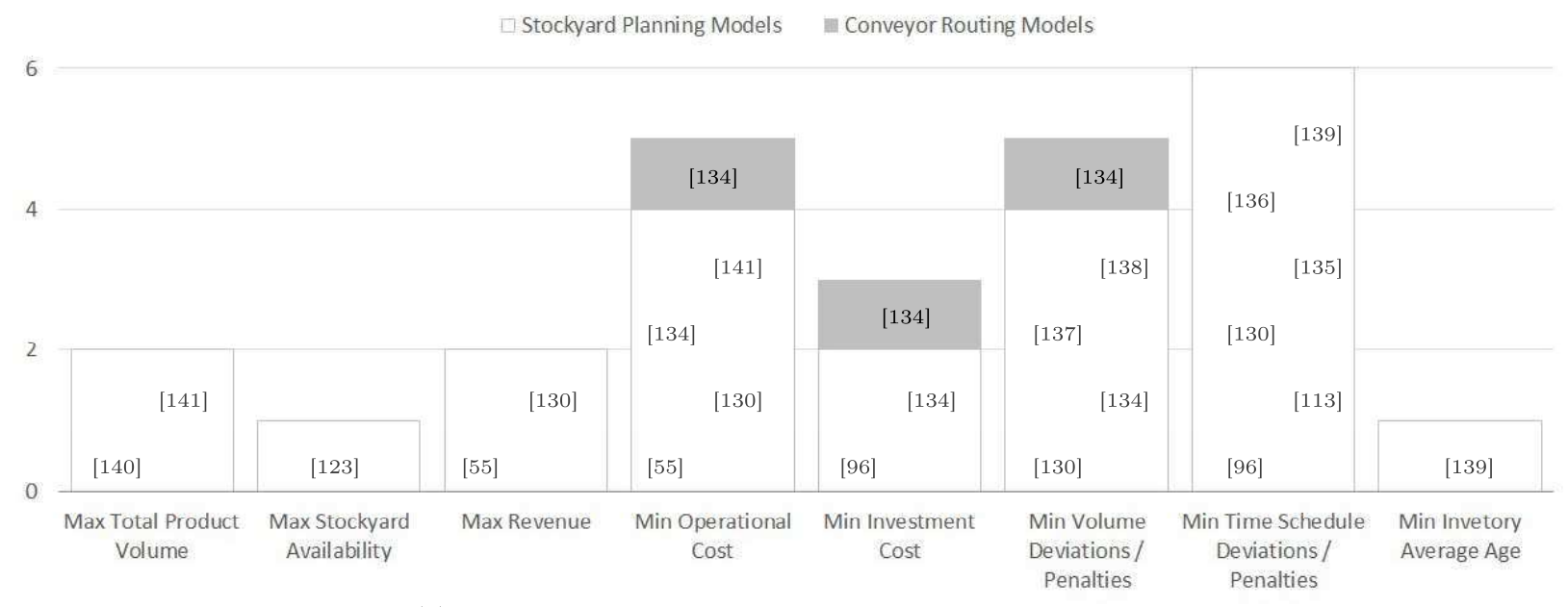

(a) Objective Functions

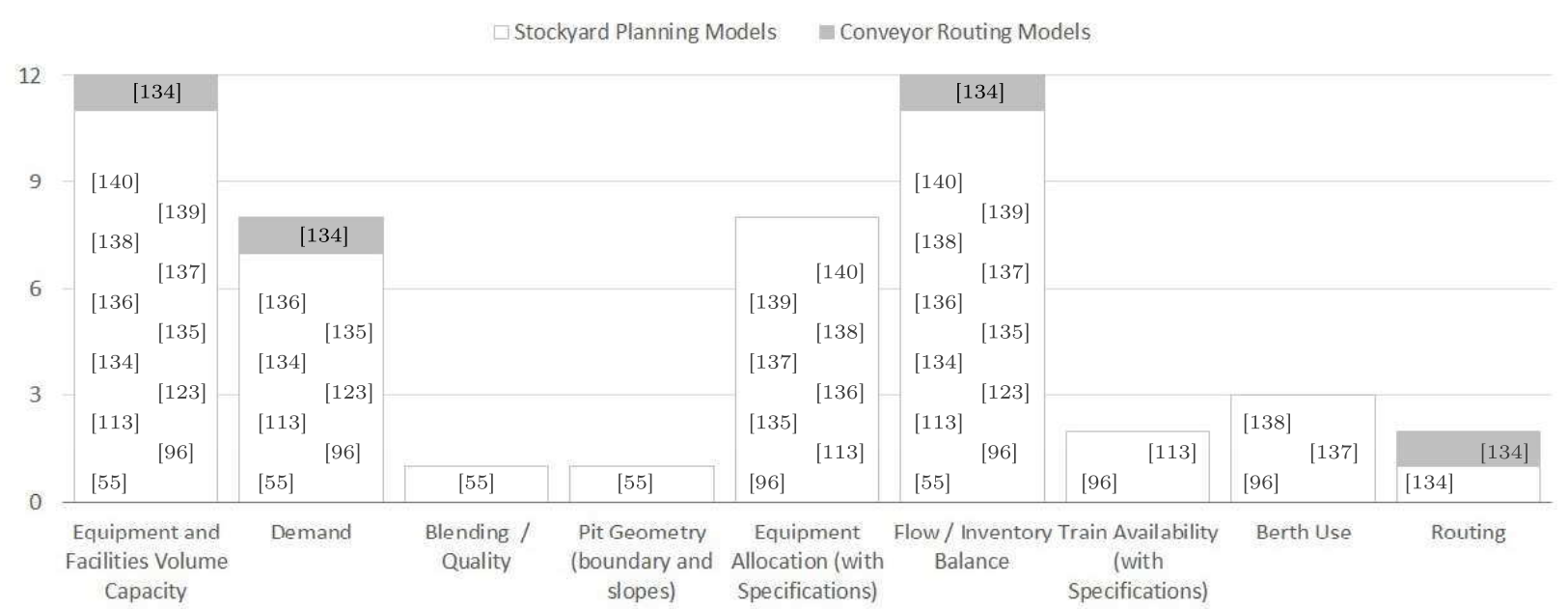

(b) Constraints

Figure 4. Port Articles

meet demand and avoid demurrage penalties.

There is a wide range of possible objectives in stockyard planning models. Some works seek to maximize the product volume, other works are concerned with minimizing operational costs. A distinct approach involves seeking to avoid contractual penalties for delayed/unsatisfied demand. For a thorough picture of the different objective functions found in the surveyed papers, see Figure $4 a)$.

With regards to the constraints, inventory balance constraints are present in all surveyed articles, often in order to define storage rules and avoid volume differences in stockpiles. Capacity constraints are also seemingly universal, as the loading and unloading capacity of the facilities and the storage area are both limited. Many papers combine stockyard planning and equipment allocation constraints. Some papers impose the constraint that demand should always be met, whereas other articles choose to maximize the output volume instead. Figure $4 \mathrm{~b}$ ) conveys the main constraints in the researched articles.

As depicted in Table 5, the vast majority of works employs deterministic approaches, perhaps due to the underlying complexity of the problem. In the group of deterministic models, Nobrega [123] developed a MILP model aimed to maximize stockyard availability with a view to improve the loading of vessels at Tubarão Port Terminal, Brazil. Ago et al. [134] worked on a MILP model with Lagrangian decomposition and coordination technique to optimize simultaneously the storage 
allocation and transportation routing at the raw materials yard. In [137; 138] we find an integer programming model with greedy construction and enumeration to optimize stockyard management. A case study was considered at HVCC, New SouthWales, Australia. Hanoun et al. [139] created a bi-objective model for stockyard planning with resources scheduling. The authors presented an effective heuristic to solve this problem and tested it on different real-life data scenarios. Belov et al. $[135,136]$ introduced a CP model with large neighbourhood search to optimize stockyard planning, considering reclaimer scheduling and vessel arrivals, and validated through HVCC real data. A tree search algorithm was proposed in Savelsbergh and Smith [140] for stockyard planning, which makes use of space-time diagram geometric properties of coal stockyard planning. The model is applied to a case study in the HVCC in Australia. Finally, Moreno et al. [55] proposed several variants of MILP models to optimize a combined version of open pit mine production scheduling with stockyard planning.

Stochastic approaches were selected in [141] and [142]. Binkowski and McCarragher [141] used queuing theory to optimize the operation of a mining stockyard. In order to solve the problem, the authors also developed a local search algorithm. In a distinct approach, Le et al. [142] utilized a DES model of a stockyard operation. The simulation allows the decision maker to evaluate the value of different production plans with respect to some performance function of interest.

\subsection{Conveyor Routing Models}

Port terminal operations generally involve the transportation of mining product from the railway to the stockyard and then from stockyard to ship by means of a conveyor belt. An operational challenge is to define the best route to transfer the product using the conveyor belt system. This problem is both complex and specific, as each port terminal has its own system design and configuration. Stochastic formulations are dominant in this type of problems, and uncertainties arise with respect to ship and train arrival, as well as machine breakdowns. Table 5 provides an outline of the stochastic and deterministic approaches found in the surveyed papers.

As previously mentioned in section 5.1, Ago et al. [134] proposed a MILP model with Lagrangian decomposition to address simultaneously storage allocation and transportation routing from the raw materials yard.

The stochastic approaches found in the literature consisted solely of discrete-event simulation models. Fioroni et al. [143] built a discrete-event simulation model of the conveyor network at COSIPA (Companhia Siderúrgica Paulista), a steel company in Southeast Brazil. Meanwhile, a model of the conveyor network system of a surface mine in China was presented in [146]. Discreteevent simulation was also applied to redesign a conveyor belt network in [145] and for the design of a ground articulating pipeline system [144]. In the latter paper, the authors claim that their approach can also be applied to conveyor belt systems.

As previously mentioned, the Conveyor routing problem can also be applied to underground mines. As an example, McNearny and Nie [147] developed a simulation model for an existing conveyor belt haulage system at an underground coal mine in Southern Utah, USA. The authors considered spillage, belt stoppage and loading variations. They tested different designs and operational modifications, and analyzed their performances.

\subsection{Literature Summary and Research Opportunities}

We listed two specific applications of OR connected to ports in the supply chain of the mining industry, namely stockyard planning models and conveyor routing models.

Since none of the surveyed articles considered environmental impacts, we believe this is an important open problem in the literature. This is reinforced by the fact that port operation is generally very demanding in terms of heavy machinery. Once again life cycle analysis (LCA) is an interesting 
tool to assess the overall impact of the activity. Furthermore, environmental aspects can be considered within the model constraints, as well as in the objective functions of multi-criteria decision analysis (MCDA) or multi-objetctive programming (MOP) models.

Stockyard planning models are found more frequently. Even though there is real world uncertainty regarding demand and machine breakdowns, for example, most articles employ deterministic approaches. Hence, we can safely state that there is a gap in the literature with regards to stochastic approaches, such as stochastic optimization, Markov decision processes, reinforcement learning, approximate dynamic programming, etc. These approaches enable the decision maker to quantify the uncertainty and use the quantification within an optimization framework.

Conveyor routing models, on the other hand, seem to be quite rare. Most of the models in the literature are concerned with building detailed discrete-event simulation models of the conveyor system, possibly due to the fact that each terminal has its own system design and belt configuration. General, reproducible models, both deterministic and stochastic, would be a very useful development in the literature.

\section{Maritime Shipping}

Often mining industries are located faraway from customers, sometimes even in another continent. In that case, maritime shipping is generally the preferred means of transportation from mine to customer.

Whereas maritime shipment has attracted considerable attention in the literature [148; 149], it is not often that this literature is directly connect to the mining industry. Shipping optimization problems include for example berth allocation, $\mathrm{CO}_{2}$ emissions control, fleet design, maritime inventory management, pilot scheduling, ship routing, ship scheduling and stowage planning [149-152]. Among these applications, one can find some works connecting vessel allocation and scheduling with the mining supply chain. It is these works that we survey in this section. Table 6 presents a summary of the researched articles, selected according to the methodology in Section 2 and Table 2 .

Table 6. Maritime Shipping Optimization Articles Classification

\begin{tabular}{c|c|c|c|c}
\hline & $\begin{array}{c}\text { Bibliographic } \\
\text { Review }\end{array}$ & Deterministic & Stochastic & $\#$ Articles \\
\hline $\begin{array}{c}\text { Allocation and } \\
\text { Scheduling } \\
\text { Models }\end{array}$ & & & & \\
\hline
\end{tabular}

\subsection{Vessel Allocation and Scheduling Models}

The Vessel allocation and scheduling problem is concerned with deciding which ships should carry the mining product to the clients and when. In particular, berth scheduling is concerned with defining a port berth for each incoming vessel, depending on the capacities of the berth and of the vessel. Such a problem typically aims to synchronize operations, considering scheduled train arrivals, stockpiling levels and vessel loading times. As such, it may become quite complex even for moderately sized operations, involving many uncertainty factors.

Vessel transport scheduling, on the other hand, is concerned with delivering the demand for the final client. As such, it involves planning, tactical and operational decisions on which type and 
quantity of vessels to employ, as well as scheduling decisions on when to deploy each vessel to transport the final product to the destination.

The most popular objective in the surveyed literature is to minimize the operational cost. Other objectives are also found in the literature, such as minimizing idle time, penalties or deviations. Figure 5a) summarizes the objectives encountered in the surveyed literature.

Upon analyzing vessel allocation and scheduling models, one finds two types of constraints that appear very frequently concerning equipment and facilities volume capacity and equipment allocation, the latter concerning the compatibility between pieces of equipment and operations, prevalent in vessel allocation decisions. Figure 5b) depicts the main constraints found in the researched articles.

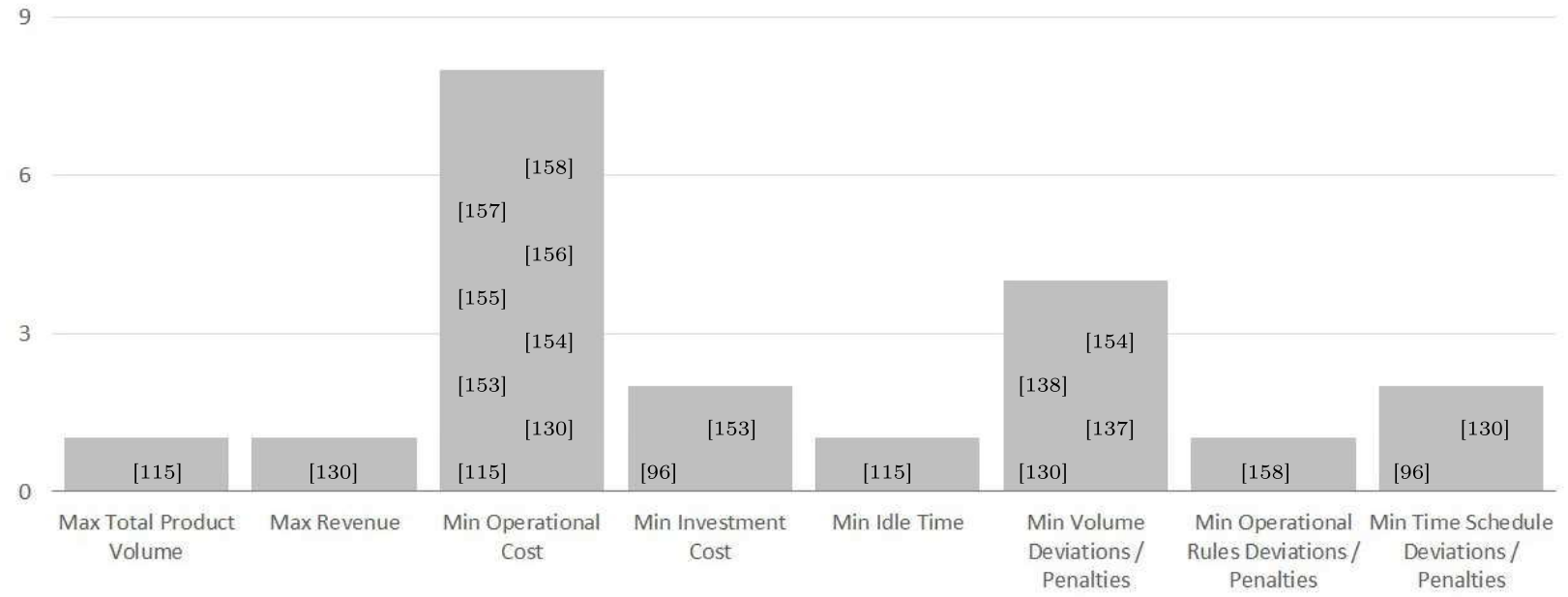

(a) Objective Functions

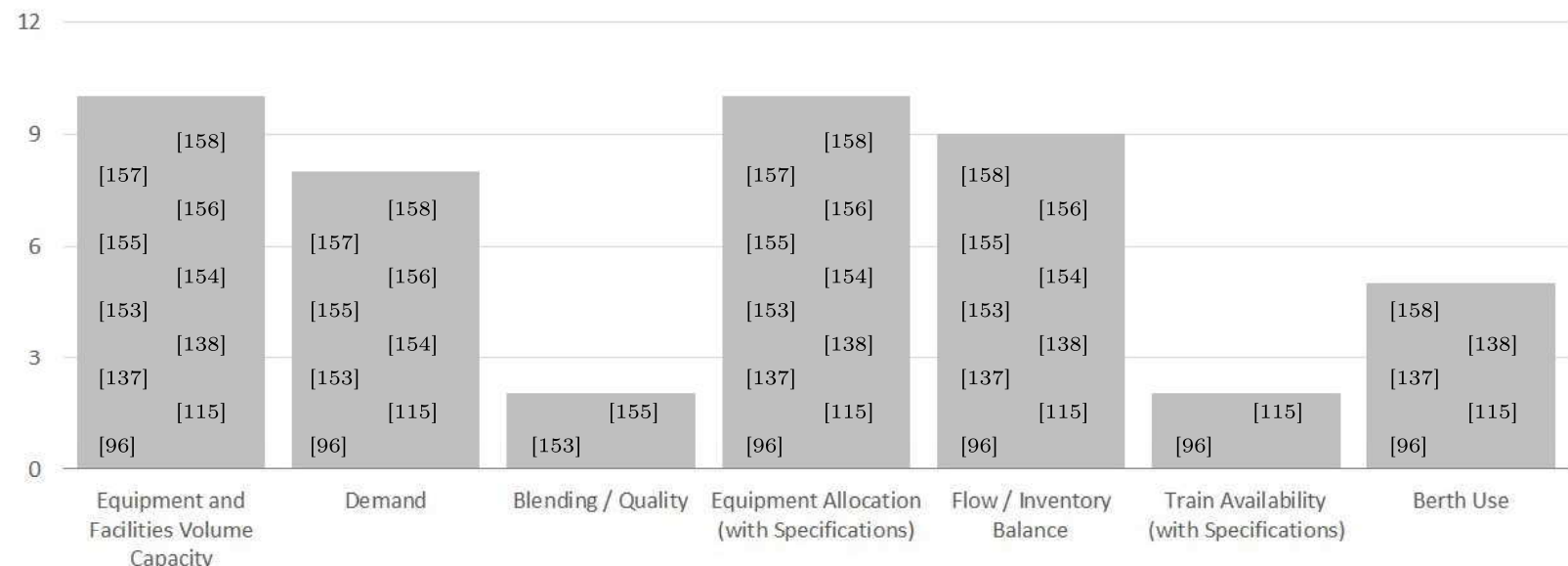

(b) Constraints

Figure 5. Maritime Shipping Articles

Two papers were found which presents a stochastic approach, as illustrated in Table 6 . Table 6 also presents many examples of deterministic models applied to vessel allocation and scheduling. Among the deterministic approaches one can find a MILP model aimed to minimize coal inventory, purchase and transportation cost [156], applied to a Taiwanese company. A model for fleet design and ship routing decisions was proposed in [157], whereas [155] features a MILP model to optimize coal fuel blending and shipping fleet design to transport coal from overseas to domestic power plants. The latter model was validated through a case study involving the coal logistics system of a local electric utility company. Meanwhile, Christiansen et al. [154] developed a constructive heuristic 
to optimize a maritime inventory routing problem faced by a cement producer in Norway. While mainly concerned with stockyard management, the model in $[137 ; 138]$ is also concerned with vessel scheduling decisions aimed to minimize ship delays. A combination of railway problem and vessel scheduling designed to have the product reach the port in time for boarding was studied in [115] and solved by means of a MILP model, with an application to the HVCC. A more ambitious formulation [153] modeled the global market of thermal coal shipment, with the objective of connecting export and import ports while also meeting the demand at each node. They utilized their model to analyze the impact of shipments and coal market changes in the worldwide flow of coal distribution.

The stochastic approach in [158] made use of a deterministic multi-period mixed integer programming model to minimize total coal purchasing and transport.The stochastic component is a scenario tree method designed to account for the uncertain coal demand.

\subsection{Literature Summary and Research Opportunities}

Similarly to railway transportation problems, maritime shipping presents many potential OR applications. However, one can find only a limited literature directly connected to mining products. Such a literature is mainly concerned with vessel allocation and scheduling, and is dominated by deterministic approaches. Hence, approaches that account for the underlying uncertainties of maritime transportation would certainly enrich the literature. In particular, approaches that can both quantify uncertainty and optimize the system under the mapped uncertainties would be welcome additions to the literature.

$\mathrm{CO}_{2}$ emission and environmental issues were also not addressed in the surveyed literature. Hence, approaches that consider the environmental burden related to the operation, as well as other objectives and stakeholders perspectives, constitute possible innovations in future research.

\section{Supply Chain}

The previous sections presented an outline of researches focused specifically on a single stage of the mining supply chain. Naturally, as it can be expected, many approaches do exist that combine multiple stages in the chain. This section is dedicated to a survey of these approaches. For an early survey paper which addressed the mine-mill-market supply chain integration, the interested reader is referred to [3].

When combining different production stages, the objective is often to determine production plans and schedules that optimize the overall supply chain performance. Another very popular problem in this context is the blending problem, as it often determines the revenue. That happens because, depending on the blending process, one can manufacture different final products which, in their turn, are sold at distinct prices [6]. Kozan and Liu [5] also highlights the importance of maintaining target composition of iron quality. Another problem in our categorization of supply chain applications is capacity expansion. Since mining is an activity that generally demands high investments, these problems are solved to optimize these investments and their return. Table 7 presents a summary of the researched literature on mining supply chain problems, selected according to the methodology in Section 2 and Table 2.

An important application of operational research in logistics is the so-called Facility Location Problem [197-200]. Despite this fact, there are few works that apply the Facility Location Problem to the mining industry. Kumral [201] applied a genetic algorithm to find a solution to a deterministic Mine Facility Location Problem. Zhou and Li [196] developed a two-stage stochastic integer programming model with compound real options to optimize a multi-echelon coal supply chain under uncertainty. Paricheh and Osanloo [41], on the other hand, took into account metal price and grade uncertainties in their work. They used a quantitative simulation-based risk management approach to solve the primary crusher location at Sungun Copper Mine (SCM) in Iran. Their results showed 


\begin{tabular}{|c|c|c|c|c|}
\hline & $\begin{array}{c}\text { Bibliographic } \\
\text { Review }\end{array}$ & Deterministic & Stochastic & \# Articles \\
\hline $\begin{array}{l}\text { Supply Chain } \\
\text { Production } \\
\text { Planning and } \\
\text { Scheduling } \\
\text { Problems }\end{array}$ & {$[3 ; 5 ; 6]$} & $\begin{array}{c}{[7 ; 19 ; 44 ; 45 ; 51 ;} \\
54-57 ; 62 ; 64 ; 65 ; \\
69 ; 96 ; 113 ; 115 ; \\
118 ; 123 ; 126- \\
129 ; 137-139 ; 153 ; \\
155 ; 156 ; 159-180]\end{array}$ & $\begin{array}{c}{[39 ; 70 ; 71 ; 73 ; 78-} \\
82 ; 84 ; 87 ; 88 ; 102 ; \\
106 ; 130 ; 158 ; 181- \\
196]\end{array}$ & 85 \\
\hline $\begin{array}{l}\text { Blending } \\
\text { Problems }\end{array}$ & {$[3 ; 5 ; 6]$} & $\begin{array}{c}{[7 ; 19 ; 44 ; 45 ; 51 ;} \\
54 ; 56 ; 57 ; 62 ; 64- \\
66 ; 69 ; 118 ; 123 ; \\
126 ; 153 ; 155 ; 159 ; \\
161-163 ; 166- \\
168 ; 170 ; 172- \\
174 ; 176-178 ; 180]\end{array}$ & $\begin{array}{c}{[39 ; 70 ; 71 ; 73 ; 78-} \\
82 ; 87 ; 88 ; 102 ; \\
106 ; 130 ; 181- \\
189 ; 191-195]\end{array}$ & 64 \\
\hline $\begin{array}{c}\text { Capacity } \\
\text { Expansion } \\
\text { Problems }\end{array}$ & {$[3 ; 6]$} & {$[96 ; 115 ; 160 ; 175]$} & {$[189 ; 190 ; 196]$} & 9 \\
\hline
\end{tabular}

that, depending on the chosen location, the project risk can increase ten times. It is worth pointing out that the discussion about mining Facility Location will be constrained to the present paragraph due to the limited literature on the subject.

\subsection{Supply Chain Production Planning and Scheduling Problems}

When the objective is to optimize overall supply chain performance, an important problem is to determine which suppliers or mines will be used and what volume will be produced for each period. OR applications dealing with this problem are collectively known as supply chain production planning and scheduling problems (SCPPSP). Models covering multiple mines, stockpiles and process are also known as "Mine complexes" models. Here, it is important to notice the difference between Mine Production Scheduling Problems (MPSP) and Supply Chain Production Planning and Scheduling Problems (SCPPSP), since both are production scheduling problems. Mine Production Scheduling Problems (MPSP) are specific to the mining activity and use the block model to divide the mines into blocks and determine when each block should be mined. Supply Chain Production Planning and Scheduling Problems (SCPPSP), on the other hand, are more general and cover more than one link of the mining supply chain. Their objective is to produce an schedule for the production at each link with a view to optimize the overall gain. Hence, these models do not need a detailed description of the mining blocks. When a model covers more than one stage of the mining supply chain and employs a block model, it is classified as both MPSP and SCPPSP [e.g., $3 ; 5 ; 6 ; 44 ; 45 ; 51 ; 54-57 ; 62 ; 64 ; 65 ; 70 ; 71 ; 73 ; 78-82 ; 84 ; 87 ; 881$. 
Perhaps due to the stochastic nature of the revenue, which depends on market fluctuations, the most common objective found in mining supply chain applications is to minimize the operational cost. Naturally, this is not the only goal in the specialized literature. Figure 6a) is included to provide an outline of the objective functions found in the researched articles.

As SCPPSP models more than one stage of supply chain, it must control the product flow between successive stages in the chain. That, in turn, imposes constraints on flow and inventory balance. Capacity constraints on pieces of equipment and facilities in general are also commonly found to deal with limited processing capacity. Since the main objective is to sell mining product to the final clients, one may also expect to find demand satisfaction constraints. Figure 6b) provides an account of the main constraints found in the literature. Combination of SCPPSP and blending will be considered in the next section.

Perhaps due to factors such as problem complexity and difficult to determine the cause and effects of uncertainties, deterministic models are prevalent, as illustrated in Table 7. However, Table 7 also shows a large body of literature covering stochastic aspects of the problem.

As often happens, deterministic approaches jump-started this research field. Early on, a LP model was proposed to optimize United States coal supply chain in [164; 165]. Somewhat later, a fuzzy bi-criteria multi-index transportation model was applied in [179] to aid decisions on the annual coal purchase and allocation plan at Taipower, an electricity company in Taiwan. In a related work, Pendharkar [172] proposed a fuzzy linear program to optimize production planning with blending constraints, applied to coal mines in Virginia, Illinois and Pennsylvania. The choice of routs to transport coal from mine to port in Colombia (including, roadway, railway and inland waterway) was approached in [171] by means of a LP model. Meanwhile, Thomas et al. [128] employed mixed integer programming to a planning and scheduling problem in Australian coal mines involving trains and terminal integration. MILP models have been applied in [113] and [129]. The former paper aimed to optimize a coal export supply chain by means of train scheduling and stockyard management decisions. They suggested that DES systems be applied to tackle the integration of those decisions. In contrast, Thomas et al. [129] employed column generation (CG) to solve a resource constrained scheduling problem, with application in a real-world coal supply chain in which all mines share the same railway. More recently, a research work proposed a decentralized approach for the coal supply chain which is comprised of three components, namely multiple independent mines, railway company and port terminal company [127]. In their column generation based decentralized approach, terminal and railway find better upper bound solutions and feed them to a coordination problem. Finally, Canales-Bustos et al. [161] proposed a multi-objective model that makes use of MILP and particle swarm metaheuristic algorithms to optimize a mining decarbonized supply chain.

Stochastic models appear in more recent papers. Bodon et al. [71] optimized an export supply chain scheduling problem with blending using LP and DES techniques. They applied the model in a coal export supply chain. To tackle demand uncertainty in a coal trade enterprise, Cheng et al. [184] employed model predictive control in conjunction with MILP. General purpose optimization experiences with mine companies were presented in Balzary and Mohais [130] which involved planning and scheduling, blending, rail and vessel scheduling, along with two examples related to iron and coal supply chains in Western Australia and Queensland. A scenario-based comparison was proposed in [169] whereby a global turnover minimizing solution was compared to the actual scenario in terms of ash emission. In order to come up with the optimized solution, the authors made use of a deterministic LP model.

\subsection{Blending Problems}

Similarly to supply chain production planning and scheduling problems, blending problems are also mainly concerned with optimizing operational costs, as illustrated in Figure 7a). As observed in Figure $7 \mathrm{a}$ ), other objective functions also appear, concerned with revenue maximization, environmental 


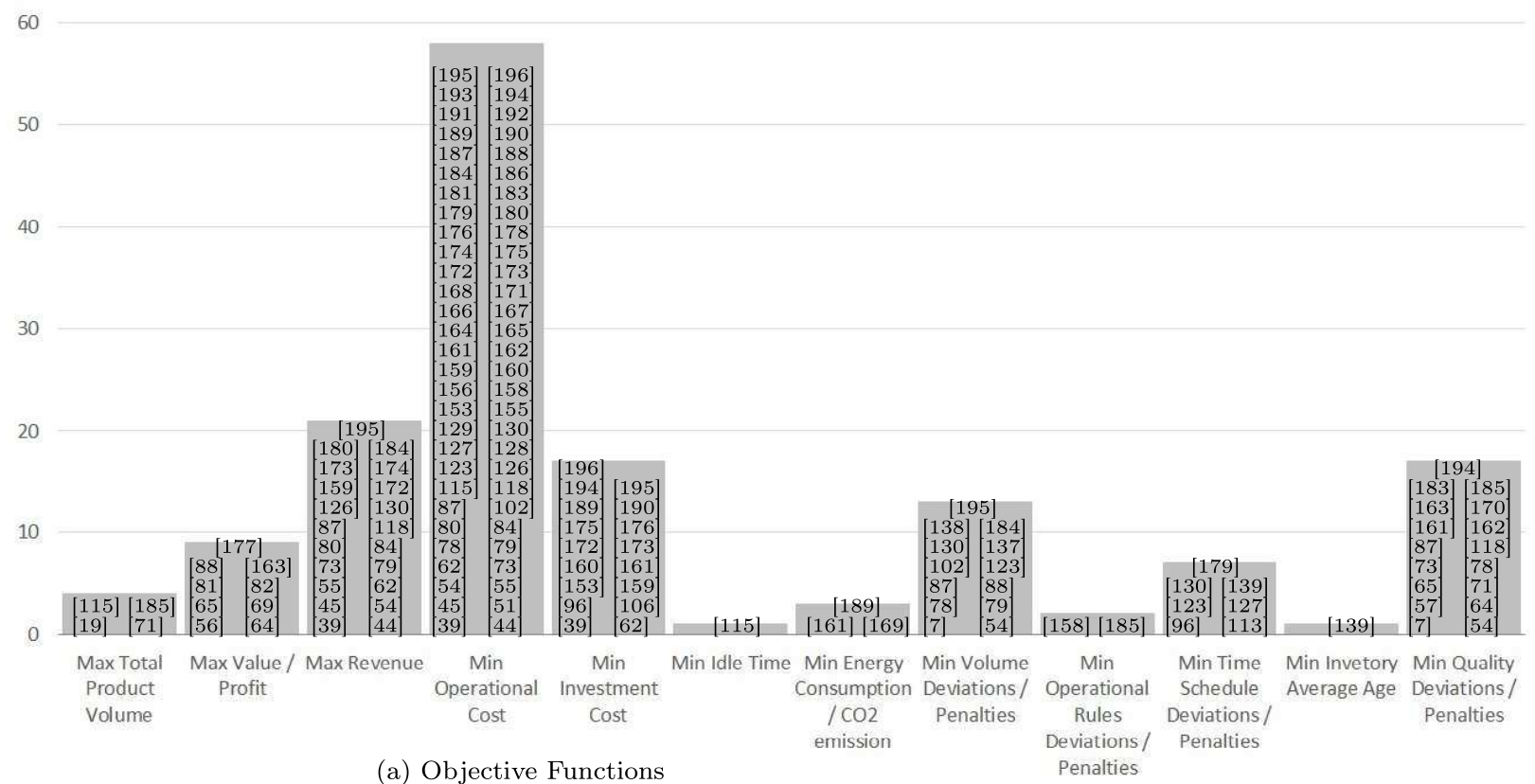

(a) Objective Functions

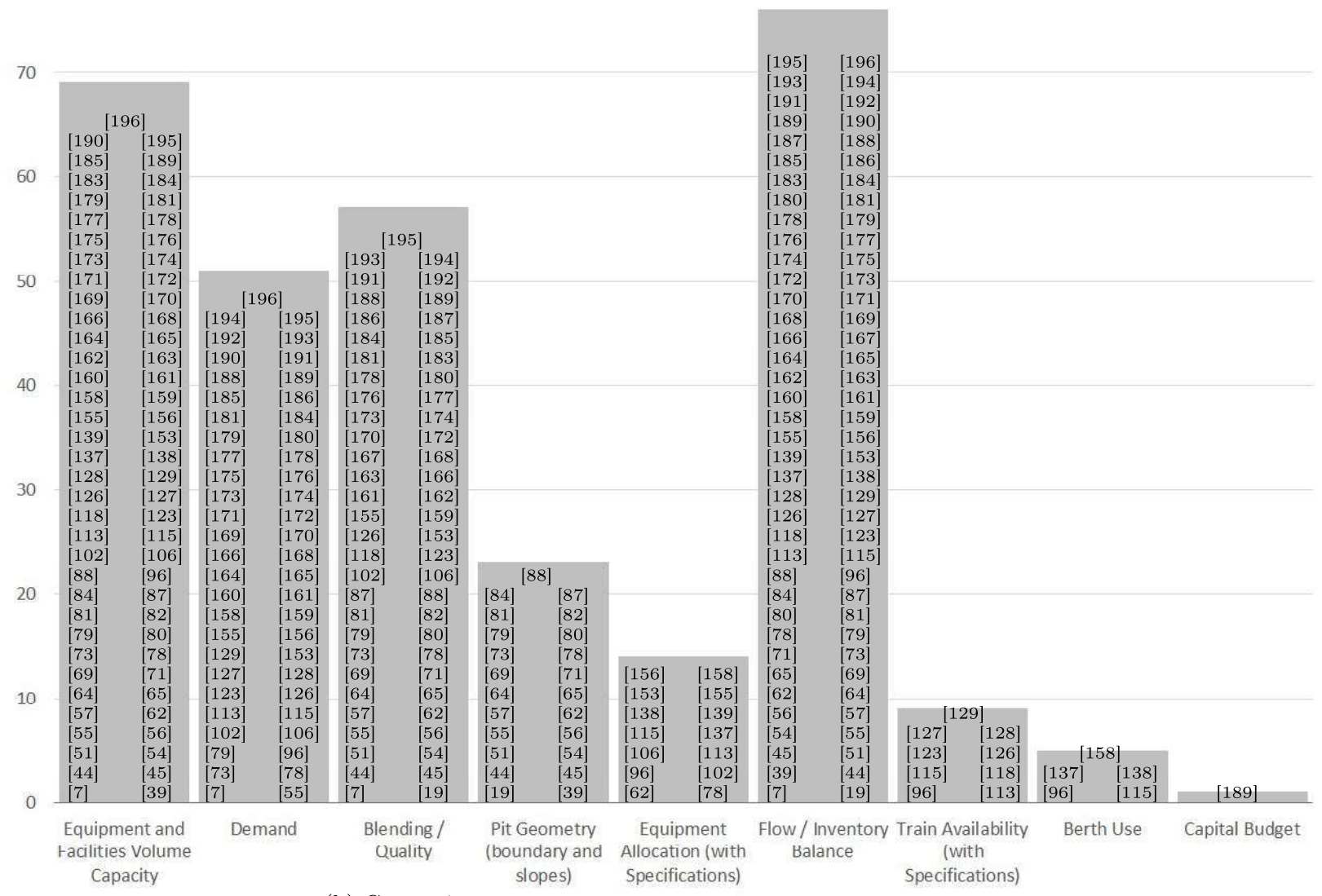

(b) Constraints

Figure 6. Supply Chain - Production Planning and Scheduling Problem Articles

indicators, deviation from quality specifications, as well as other aspects of the operation.

A very important characteristic of a mining product is its quality, often related to the chemical composition of the mineral ore. Products are generally specified by required target levels (intervals) of certain key chemical elements. The addition of quality assurance constraints to supply chain production planning and scheduling problems gives rise to blending problems. Consequently, blending 
problems must have blending constraints. A by-product of that is the additional need for flow and inventory balance constraints, which also seem to be universal in blending problems. Capacity and demand constraints are also common in the literature, as observed in Figure $7 \mathrm{~b}$ ), which summarizes the main constraints found in the literature.
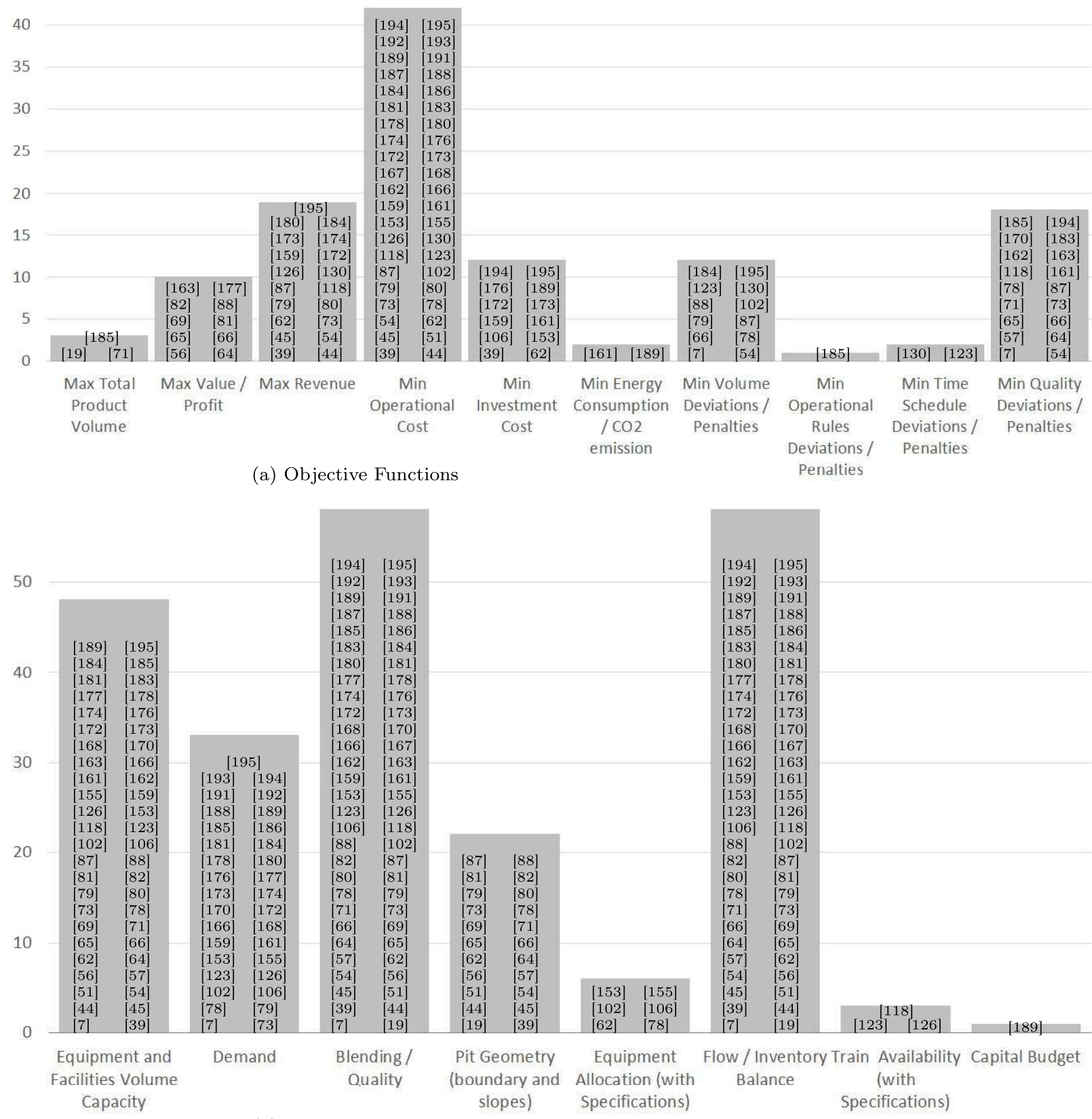

(b) Constraints

Figure 7. Supply Chain - Blending Problems Articles

Table 7 presents a graphical feature of deterministic and stochastic approaches for the blending problem. Similarly to the other topics covered in this research, deterministic models are prevalent. However, one can also observe a large portion of the literature considering uncertain aspects of the problem, around $42 \%$ of the surveyed works.

Among the deterministic models, it is worth highlighting an early work by Ravindran and Hanline [176], which develops a MILP model to find optimal locations for blending plants and applies the 
model to the state of Indiana, USA. Later, Barbaro and Ramani [159] were concerned with selecting processing facilities and scheduling the production of a coal plant system. To solve the problem, they made use of a MILP model. Sherali and Puri [178], on the other hand, studied a similar problem designed to optimize blending and distribution and modeled by means of three distinct LP models, which were applied to the Westmoreland Coal Company. The three models are rather similar, differing on the level of simplification they apply to the complexities arising in the realworld supply chain. A different approach was proposed in [163], which employs a multi-objective linear goal programming model for the blending problem. In the same trend, Lyu et al. [170] developed a goal programming model to minimize coal requirements deviation with an application to a real-world problem at Hsinta Power Station. In contrast, a MILP formulation is proposed in [166] to minimize total coal shipping and purchasing cost with blending constraints at a Taiwanese power company. In Brazil, Nobrega [123] developed two complementary models to optimize Vale's Southeast system supply chain, aiming to maximize ore throughput while also accounting for vessel delay penalties. The developed models make use of linear and integer programming techniques. These same techniques were employed in a binary model solved by heuristic techniques and aimed at optimizing coal shipping and blending at an electricity company in Taiwan [168]. Some time later, to optimize coal mines supply chain in neighboring China, Peng et al. [174] developed a linear programming model applied to Xuzhou's coal mines supply chain. More recently, Schellenberg et al. [177] evaluated the performance of genetic algorithms for nine instances of the coal blending problem, comparing it to LP. A different study, Kumar and Chatterjee [54] developed a scheduling model with both scheduling and stockpiling constraints, applying it to a large open-pit coal mine in India.

Despite the complexity of the problem, one can also find non-linear formulations designed to convey a better representation of the system. For a non-linear formulation to the production scheduling of coal mines, we refer to [173]. A more involved model for the coal blending problem was proposed in [167] which combines non-linear fuzzy neural network and genetic algorithm. A different approach was applied by Xi-Jin et al. [180], who employed simulated annealing to solve a non-linear formulation of the coal scheduling and blending problem.

The blending problem is subject to many uncertainties, one of which is the very composition of the arriving product. In Candler [183], such an uncertainty was introduced in a deterministic MILP model by means of a sampling strategy with certainty equivalence. Uncertainties in the product composition were also considered in the multi-objective chance-constrained formulation introduced in [194] for the coal blending problem, which was applied to 6 case studies. The same modeling approach was applied by Kumral [187], who applied multi-objective chance-constrained programming to minimize blending cost, also considering quality variability. In a different direction, Conradie et al. [185] developed a generic linear goal programming model for a multi-objective problem, considering demand variability by means of simulation scenarios. A number of works employed chance-constrained models for the brass casting industry [191-193] under quality variations, with a case study at MKEK brass factory in Kırıkkale, Turkey. Montiel and Dimitrakopoulos [79] built a stochastic programming model to solve mine production scheduling combined with processing and transport planning, under different scenarios of geological uncertainty. The method is applied to a mining complex that produces copper and contains two different pits. Other stochastic programming approaches appear in [73; 181; 195]. Arigoni [181] developed optimization models to help US power plants evaluate their purchase strategy under market changes. Goodfellow and Dimitrakopoulos $[73,88]$ proposed a two-stage model that includes mine extraction uncertainty and non linear transformations during production process. The two-stage model in [195], in contrast, accounts for uncertainties both in ore supply and comodity market (price and demand). The model details mine, stocks, plants and delivery to the final customer, but not the transportation and port operation. Finally, a DES model is applied in [182] to a coal supply chain. The model, which encompasses planning and blending decisions, was applied to a case study at PT Kaltim Prima Coal (KPC) in Indonesia. 
Another way to tackle uncertainty is fuzzy logic, applied in [162] in the context of a multi-objective blending problem. In a similar yet distinct setting, Li et al. [188] proposed an inexact fuzzy coal blending model (IFCBM), with interval linear programming (ILP) and fuzzy linear programming (FLP) to solve the coal planning and blending problem. Additionally, Dai et al. [186] proposed a simulation-based fuzzy possibilistic programming approach for the coal blending problem. The model was tested in a real-case power plant in Gaojing and Shijingshan,in the west of Beijing.

Environment constraints appear in some works regarding blending problems. Generally, they impose limits to ash contents. Most of the literature consists in articles on coal mining [54; 153; $155 ; 162 ; 163 ; 166-168 ; 170 ; 172-174 ; 176-178 ; 180 ; 181 ; 185 ; 186 ; 188 ; 189 ; 194]$. The exception is [19], which addresses phosphate mining.

\subsection{Capacity Expansion Problems (CEP)}

Depending upon the considered time horizon, an analysis of the production planning and scheduling problem must consider possible changes to the facilities. Since expanding capacity is often expensive and involves projecting future demand, the expansion of an existing facility or the addition of a new one requires very careful consideration. Deciding upon expansion process is the main motivation of the so-called capacity expansion problems [202].

As occurred with previous Mining Supply Chain articles, to Minimize Operational Cost is a often the objective. We found Minimize Investment Cost very frequently as well, because generally capacity expansion incurs in investment cost. Figure 8a) show the different objective functions found in the researched articles.

With regards to the problem's constraints, flow constraints are always present, mainly because planning capacity also involves projecting future operations. Naturally, since we are considering whether or not to expand capacity, capacity constraints must always apply. Moreover, since the expansion project is generally conceived to meet future demand, one can also expect demand constraints to be always part of the formulation. Observe in Figure 8b) that the preceding constraints are, in fact, part of all surveyed formulations. Note also that Figure 8b) lists several additional constraints, which depend on the formulation applied.

While capacity expansion is a consolidated problem in the literature, we found a modest number of applications to mining supply chain. The surveyed papers are well distributed between deterministic and stochastic models, as depicted in Table 7.

The surveyed papers on capacity expansion are fairly recent, which demonstrates that this is a relevant problem for present research. Once again, linear and integer models tend to be prevalent. Singh et al. [96] applied MILP to find an optimal expansion plan for the HVCC Supply Chain. Different heuristics are applied to speed up the convergence time. Another MILP model was employed in [160] for the storage location problem in a coal supply chain, applying their results to a real-world case study. Finally, another MILP formulation was applied to a coal supply chain in Thailand Promban and Kittithreerapronchai [175].

Among the stochastic models, Liu et al. [189] developed an inexact coupled coal and power management (ICCPM) model with uncertainty. To solve it, the authors mixed chance-constrained programming (CCP), interval linear programming (ILP) and MILP techniques. Pimentel et al. [190] suggested a multi-stage stochastic mixed-integer programming approach to solve the stochastic capacity planning and dynamic network design problem (SCPDNDP). They use scenario analysis combined with MILP to tackle demand uncertainty. They also developed a Lagrangian Heuristic to speed up computational time. The authors used a Brazilian global mining company supply chain example to evaluate the model. Zhou and Li [196] developed a two-stage stochastic MILP model with non-convex generalized Bender decomposition (NGBD) and Lagrangean relaxation to optimize coal supply chain. The authors also built a deterministic model and a mixed non-linear programming model to compare final results. 


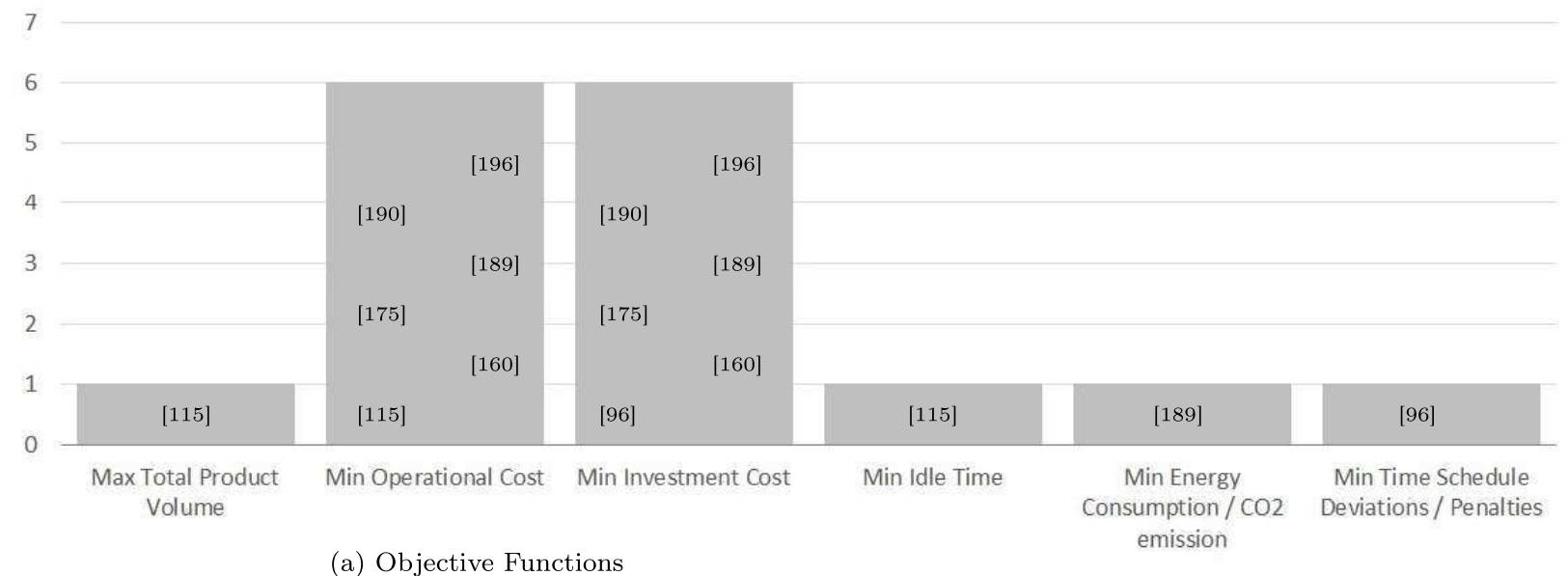

(a) Objective Functions

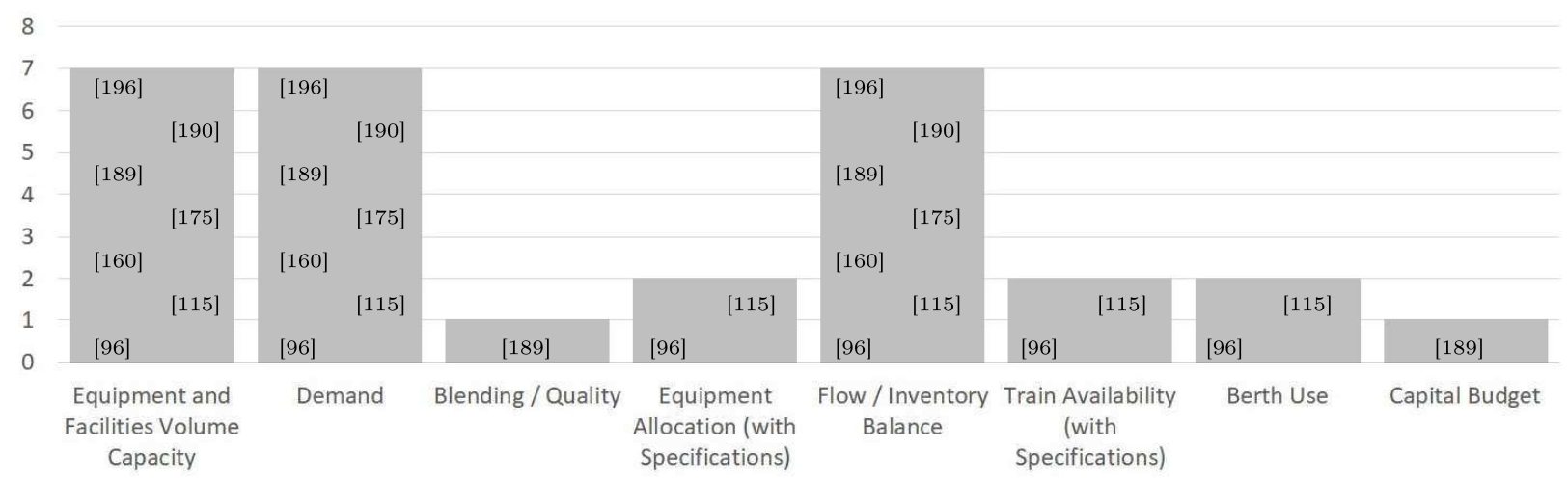

(b) Constraints

Figure 8. Supply Chain - Capacity Expansion Problems Articles

\subsection{Literature Summary and Research Opportunities}

One can find a significant number of work dealing with more than one link in the mining supply chain. Interestingly, researches involving multiple links generally address production planning and scheduling. As we are connecting links of the chain, it makes sense that these works present flow constraints, which are prevalent. As often happens, deterministic linear models are mostly used. Nonetheless, one still can find a significant number of stochastic approaches.

The blending problem is also commonly found in supply chain approaches. Blending is often necessary since the products are not uniform over the mines. Blending is also very important in other industries, such as oil \& gas and chemical, where the final product is a mix of a number of supplies. As it happens with scheduling problems, linear deterministic models are prevalent. However, one can also find a considerable number of stochastic approaches.

Capacity expansion decision also involve the analysis of multiple links of the chain. However, not many applications are found in the literature specifically related to the mining industry. Once again, the majority of the literature features deterministic approaches.

In coal mining, there are a many blending models that impose constraints with respect to ash emission. When it comes to iron ore models, however, only a small number of them address environmental issues, such as $\mathrm{CO}_{2}$ or ash emissions. We believe that new studies in this area have the potential to greatly contribute to both the industry and the society in general.

Finally, we hope that IoT, with online monitoring of the whole supply chain, will become a reality and it will contribute for more complex models with faster responses to day-to-day operational problems. 


\section{Research opportunities}

Due to the complex nature of mining operations and also to the often large distance between mines and consumers, the mining supply chain is a fertile ground for OR applications. Some applications are concerned with optimizing planning and operation of a single link in the chain. Among these applications, mining operations are the subject of large body of research. Port and railway transportation have received considerably less attention in the literature, hence present more research gaps to be bridged. Still, one can argue that the latter topics motivated a fair amount of scientific works. Maritime shipping, on the other hand, attracted only limited attention and therefore presents even larger research gaps and opportunities.

As it can be expected, the mining industry has some peculiar features. However, one can also argue that its supply chain does present some similarities with respect to other industries. In that respect, the number of papers regarding specific topics within the mining industry seems to be inversely proportional to the number of industries that share this topic. For instance, mine production scheduling and mine layout design are rather specific and one can find a vast literature on these subjects. On the other hand, train scheduling and vessel allocation and scheduling are rather general, and we find a rather limited number of applications to the mining industry. Hence, the application of optimization techniques developed in related fields to the mining industry is a fertile ground for new research. Inside mining industry, Underground Mine models are a recent research topic. Due to their complexity, they are an interesting area for future developments.

Ash control is a fairly common environmental concern in coal mining articles with blending models. On the other hand, only 4 of all surveyed articles placed the minimization of $\mathrm{CO}_{2}$ emissions as one of their objectives $[95 ; 161 ; 169 ; 189]$. As might be expected, most of these articles are fairly recent, as it is shown in Figure 9d). Given the volumes transported and the distances traveled, it is undeniable that the $\mathrm{CO}_{2}$ footprint of this industry is high. Consequently, it is fair to expected that this theme will be increasingly present in future researches.

The application of "Machine Learning" and "Artificial Intelligence" techniques to the mining industry should, in all likelihood, increase in the next years. We also expect IoT to provide an evolution in OR models in the mining industry. There will be more online information on the traceability of the equipment and the system. Such a wealth of data will allow the creation of more complex models for day-to-day problems, which can be expected to anticipate problems and bring faster responses to them.

An important classification of the literature is with regards to the assumptions on the variability of model parameters. There is a predominance of deterministic (65.2\%) models against stochastic models (34.8\%). However, as previously stated, while the early literature is nearly entirely deterministic, stochastic approaches have gained ground in recent research. With regards to the modeling choice among stochastic approaches, discrete-event simulation, conditional simulation and chanceconstrained programming have received the larger share of attention. However, one can also find stochastic programming, interval programming and queuing models as well. Figure 9a) conveys a summary of the stochastic approaches found in the literature. One can see that the number of approaches is still limited. For example, one can notice the absence of Markov models, reinforcement learning and approximate dynamic programming. It is clear that a greater variety of stochastic approaches is desirable in the near future. We believe that new approaches and techniques have the potential to generate innovations in this field. Finally, Figure 9c) shows that stochastic approaches tend to be more recent than deterministic ones..

We observed that, while nearly $50 \%$ of the researched literature combine multiple links of the mining supply chain, as illustrated in Figure 9b), these articles typically cover only a couple of links. We found only one work dealing with the four links in the chain, namely [96], which studies a problem involving mine, railway, port and shipping. This indicates that there are many research opportunities in supply chain modeling. Considering also the gap in the stochastic models, applications involving multiple links and distinct stochastic modeling techniques can provide interesting and welcome 
contributions to the literature.

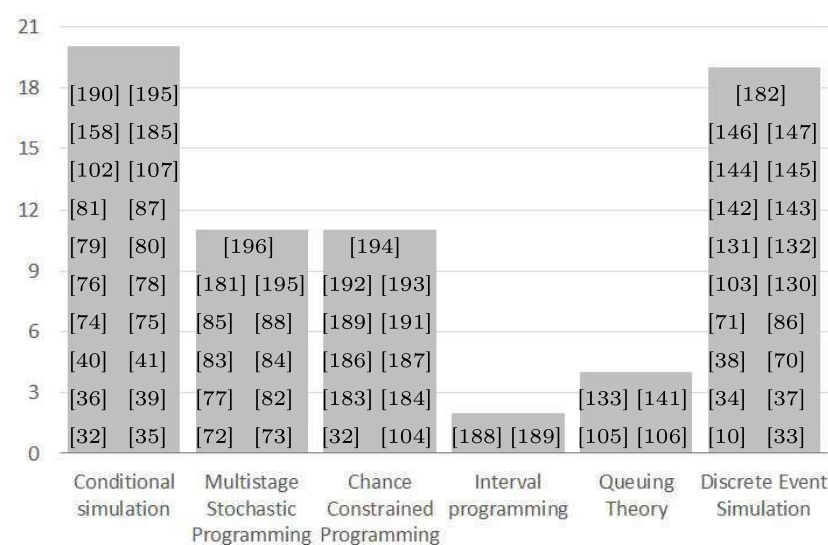

(a) Stochastic Models

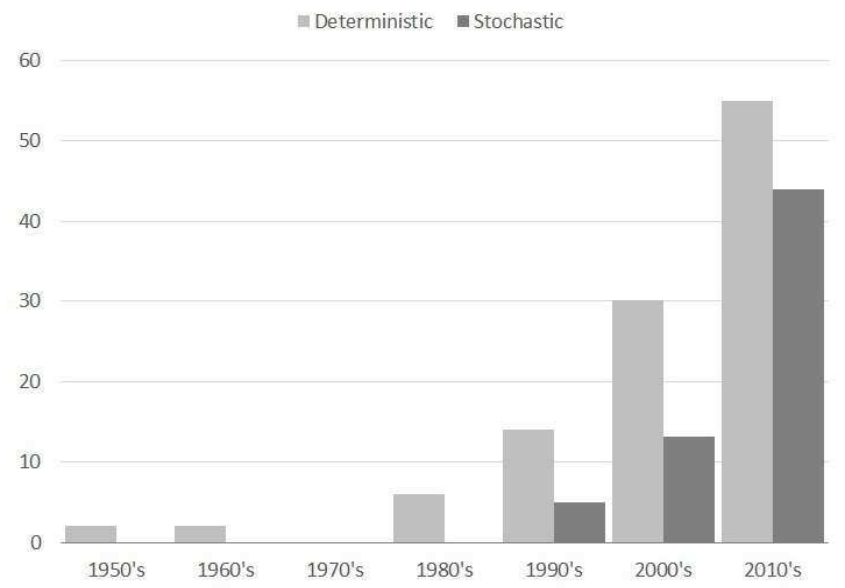

(c) Stochastic and Deterministic works over the decades

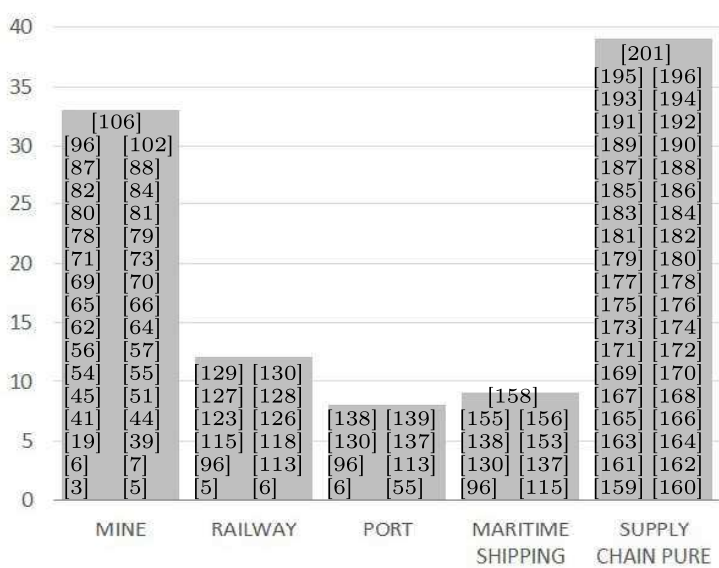

(b) Each Supply Chain Link Combined Problems

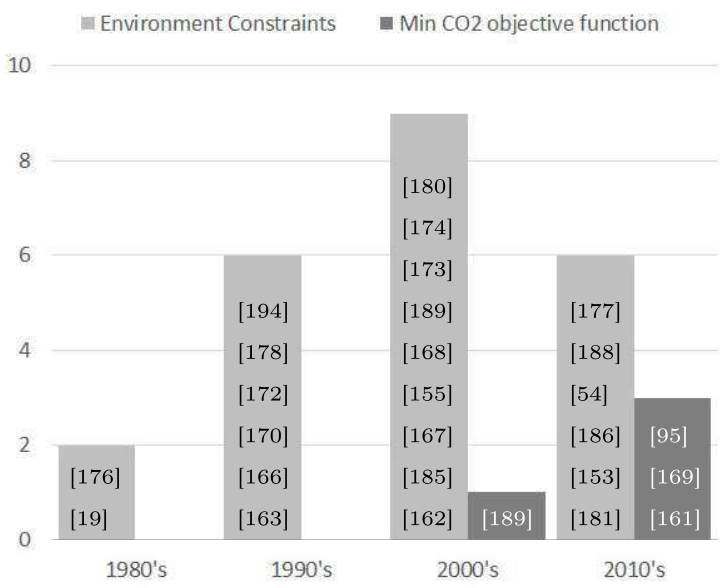

(d) Environment articles over the decades

Figure 9. Research opportunities

\section{Concluding Remarks}

This article covered state-of-the-art applications of operational research techniques to mining problems. It found the existing modeling techniques and pointed out research gaps and opportunities for future research. We believe that future models will focus on environment issues and will enjoy IoT, ML and AI benefits, providing faster responses to more complex problems. We also believe that future literature should involve a wider variety of stochastic models and cover multiple aspects of the chain.

\section{Acknowledgements}

The authors would like to thank the Carlos Chagas Filho Foundation for Research Support of the State of Rio de Janeiro, FAPERJ, for supporting the research by means of Grant no. E$26 / 202.789 / 2015$. This work was partially supported by the National Council for Scientific and 
Technological Development - CNPq, under grants \#311075/2018-5 and \#305180/2016-9. This study was financed in part by the Coordenação de Aperfeiçoamento de Pessoal de Nível Superior - Brasil (CAPES) - Finance Code 001.

\section{References}

[1] Statista. Mining - Statistics \& Facts, 2017. URL https://www.statista.com/topics/1143/ mining/.

[2] Técnico e Mineração. Mineração no Brasil Atual e sua Influência na Economia Nacional, 2014. URL https://tecnicoemineracao.com.br/ mineracao-brasil-atual-e-sua-influencia-na-economia-nacional/.

[3] T. Bjørndal, I. Herrero, A. Newman, C. Romero, and A. Weintraub. Operations research in the natural resource industry. International Transactions in Operational Research, 19(1-2):39-62, 2012. ISSN 1475-3995. . URL http://dx.doi.org/10.1111/j.1475-3995.2010.00800.x.

[4] L. Caccetta. Application of optimisation techniques in open pit mining. In Handbook of operations research in natural resources, pages 547-559. Springer, 2007.

[5] E. Kozan and S.Q. Liu. Operations research for mining : a classification and literature review. ASOR Bulletin, 30(1):2-23, 2011. URL https://eprints .qut.edu.au/48661/.

[6] B.S. Pimentel, G.R. Mateus, and F.A. Almeida. Mathematical models for optimizing the global mining supply chain. In Intelligent Systems in Operations: Methods, Models and Applications in the Supply Chain, pages 133-163. IGI Global, 2010. ISBN 9781615206063. URL https://books.google.com. $\mathrm{br} /$ books? id $=2 \mathrm{f} 7 \mathrm{Qj} \times 30 \circ \mathrm{fC}$.

[7] F.P. Costa. Aplicaçôes de técnicas de otimização a problemas de planejamento operacional de lavra em minas a céu aberto. PhD thesis, PPGEM-UFOP, Ouro Preto, MG, Brasil, 2005.

[8] A.M. Newman, E. Rubio, R. Caro, A. Weintraub, and K. Eurek. A Review of Operations Research in Mine Planning. Interfaces, 40(3):222-245, 2010.

[9] M. Osanloo, J. Gholamnejad, and B. Karimi. Long-term open pit mine production planning: a review of models and algorithms. International Journal of Mining, Reclamation and Environment, 22(1): $3-35,2008$. .

[10] M.G. Raj, H. Vardhan, and Y.V. Rao. Production optimisation using simulation models in mines: a critical review. International Journal of Operational Research, 6(3):330-359, 2009. .

[11] M. Ataee-Pour. A Critical Survey of the Existing Stope Layout Optimization Techniques. Journal of Mining Science, 41(5):447-466, 2005. ISSN 1573-8736. . URL https://doi.org/10.1007/ s10913-006-0008-9.

[12] C. Meagher, R. Dimitrakopoulos, and D. Avis. Optimized open pit mine design, pushbacks and the gap problem-a review. Journal of Mining Science, 50(3):508-526, 2014. ISSN 1573-8736. . URL https://doi.org/10.1134/S1062739114030132.

[13] A.S. Nhleko, T. Tholana, and P.N. Neingo. A review of underground stope boundary optimization algorithms. Resources Policy, 2018. ISSN 0301-4207. . URL http://www.sciencedirect.com/ science/article/pii/S0301420717303495.

[14] C. Alford, M. Brazil, and D.H. Lee. Optimisation in underground mining. In Handbook of operations research in natural resources, pages 561-577. Springer, 2007.

[15] C. Musingwini. Optimization in underground mine planning - developments and opportunities. Journal of the Southern African Institute of Mining and Metallurgy, 116:809-820, 2016. ISSN 2225-6253.

[16] M R Ahmadi and R S Shahabi. Cutoff grade optimization in open pit mines using genetic algorithm. Resources Policy, 55:184-191, 2018. ISSN 0301-4207. . URL http://www.sciencedirect.com/ science/article/pii/S030142071730404X.

[17] D S Hochbaum and A Chen. Performance Analysis and Best Implementations of Old and New Algorithms for the Open-Pit Mining Problem. Operations Research, 48(6):894-914, 2000. . URL https://pubsonline.informs.org/doi/abs/10.1287/opre.48.6.894.12392.

[18] B. King, M. Goycoolea, and A. Newman. Optimizing the open pit-to-underground mining transition. European Journal of Operational Research, 257(1):297-309, 2017. ISSN 0377-2217. . URL http: //www.sciencedirect.com/science/article/pii/S0377221716305586. 
[19] D Klingman and N Phillips. Integer programming for optimal phosphate-mining strategies. Journal of the Operational Research Society, 39(9):805-810, 1988. .

[20] H Lerchs and F Grossman. Optimum design of open pit mines. CIM Bulletin, 58(633):47-54, 1965.

[21] M. Rahmanpour and M. Osanloo. A decision support system for determination of a sustainable pit limit. Journal of Cleaner Production, 141:1249-1258, 2017. ISSN 0959-6526. . URL http: //www.sciencedirect.com/science/article/pii/s0959652616315530.

[22] Y A Sari and M Kumral. Dig-limits optimization through mixed-integer linear programming in openpit mines. Journal of the Operational Research Society, 69(2):171-182, 2018. . URL https://doi. org/10.1057/s41274-017-0201-z.

[23] R Underwood and B Tolwinski. A mathematical programming viewpoint for solving the ultimate pit problem. European Journal of Operational Research, 107(1):96-107, 1998. ISSN 0377-2217. . URL http://www.sciencedirect.com/science/article/pii/S0377221797001410.

[24] D Whittle, M Brazil, P A Grossman, J H Rubinstein, and D A Thomas. Combined optimisation of an open-pit mine outline and the transition depth to underground mining. European Journal of Operational Research, 2018. ISSN 0377-2217. . URL http://www.sciencedirect.com/science/ article/pii/S0377221718301000.

[25] M.W.A. Asad. Optimum cut-off grade policy for open pit mining operations through net present value algorithm considering metal price and cost escalation. Engineering Computations, 24(7):723-736, 10 2007. ISSN 0264-4401. .

[26] M.W.A. Asad and E. Topal. Net present value maximization model for optimum cut-off grade policy of open pit mining operations. Journal of the Southern African Institute of Mining and Metallurgy, 111:741-750, 2011. ISSN 2225-6253.

[27] E. Jélvez, N. Morales, and H. Askari-Nasab. A new model for automated pushback selection. Computers $\&$ Operations Research, 4 2018. ISSN 0305-0548. .

[28] M.R. Ahmadi and A.A. Bazzazi. Cutoff grades optimization in open pit mines using meta-heuristic algorithms. Resources Policy, 60:72-82, 3 2019. ISSN 0301-4207. .

[29] M. Osanloo and M. Ataei. Using equivalent grade factors to find the optimum cut-off grades of multiple metal deposits. Minerals Engineering, 16(8):771-776, 8 2003. ISSN 0892-6875. . URL https://www.sciencedirect.com/science/article/abs/pii/S0892687503001638.

[30] E. Topal and J. Sens. A new algorithm for stope boundary optimization. Journal of Coal Science and Engineering (China), 16(2):113-119, 6 2010. ISSN 1006-9097.

[31] D.S.S. Sandanayake, E. Topal, and M.W. Ali Asad. A heuristic approach to optimal design of an underground mine stope layout. Applied Soft Computing, 30:595-603, 5 2015. ISSN 1568-4946. .

[32] N. Grieco and R. Dimitrakopoulos. Managing grade risk in stope design optimisation: probabilistic mathematical programming model and application in sublevel stoping. Mining Technology, 116(2): 49-57, 6 2007. ISSN 1474-9009.

[33] M.W.A. Asad and R. Dimitrakopoulos. Implementing a parametric maximum flow algorithm for optimal open pit mine design under uncertain supply and demand. Journal of the Operational Research Society, 64(2):185-197, 2013. ISSN 1476-9360. . URL https://doi.org/10.1057/jors.2012.26.

[34] S Chatterjee, M R Sethi, and M W A Asad. Production phase and ultimate pit limit design under commodity price uncertainty. European Journal of Operational Research, 248(2):658-667, 2016. ISSN 0377-2217. . URL http://www. sciencedirect.com/science/article/pii/S0377221715006451.

[35] R. Dimitrakopoulos. Conditional simulation algorithms for modelling orebody uncertainty in open pit optimisation. International Journal of Surface Mining, Reclamation and Environment, 12(4):173-179, 1998. . URL https://doi.org/10.1080/09208118908944041.

[36] R. Dimitrakopoulos, C.T. Farrelly, and M. Godoy. Moving forward from traditional optimization: grade uncertainty and risk effects in open-pit design. Mining Technology, 111(1):82-88, 2002. . URL https://doi.org/10.1179/mnt.2002.111.1.82.

[37] R. Dimitrakopoulos, L. Martinez, and S. Ramazan. A maximum upside / minimum downside approach to the traditional optimization of open pit mine design. Journal of Mining Science, 43(1):73-82, 1 2007. ISSN 1573-8736. . URL https://doi .org/10.1007/s10913-007-0009-3.

[38] P A Dowd. Risk assessment in reserve estimation and open-pit planning. Transactions of the Institution of Mining and Metallurgy(Section A: Mining Industry), 103, 1994.

[39] B. Groeneveld and E. Topal. Flexible open-pit mine design under uncertainty. Journal of Mining Science, 47(2):212-226, 3 2011. ISSN 1062-7391. . URL http://link.springer.com/10.1134/ 
S1062739147020080.

[40] I. Farmer and R. Dimitrakopoulos. Schedule-based pushback design within the stochastic optimisation framework. International Journal of Mining, Reclamation and Environment, 32(5):327-340, 72018. ISSN 1748-0930.

[41] M. Paricheh and M. Osanloo. A simulation-based risk management approach to locating facilities in open-pit mines under price and grade uncertainties. Simulation Modelling Practice and Theory, 89: 119-134, 12 2018. ISSN 1569-190X.

[42] M. Blom, A.R. Pearce, and P.J. Stuckey. Short-term planning for open pit mines: a review. International Journal of Mining, Reclamation and Environment, 0(0):1-22, 2018.

[43] J Amaya, D Espinoza, M Goycoolea, E Moreno, T Prevost, and E Rubio. A scalable approach to optimal block scheduling. In Proceedings of APCOM, pages 567-575, 2009.

[44] H Askari-Nasab, K Awuah-Offei, and H Eivazy. Large-scale open pit production scheduling using Mixed Integer Linear Programming. International Journal of Mining and Mineral Engineering, 2(3): 185-214, 2010. .

[45] H Askari-Nasab, Y Pourrahimian, E Ben-Awuah, and S Kalantari. Mixed integer linear programming formulations for open pit production scheduling. Journal of Mining Science, 47(3):338, 2011. ISSN 1573-8736. .

[46] E Busnach, A Mehrez, and Z Sinuany-Stern. A Production Problem in Phosphate Mining. The Journal of the Operational Research Society, 36(4):285-288, 1985. ISSN 01605682, 14769360. URL http: //www. jstor.org/stable/2582414.

[47] L. Caccetta and S.P. Hill. An Application of Branch and Cut to Open Pit Mine Scheduling. Journal of Global Optimization, 27(2):349-365, 2003. ISSN 1573-2916.

[48] R Chicoisne, D Espinoza, M Goycoolea, E Moreno, and E Rubio. A new algorithm for the open-pit mine scheduling problem, 2009.

[49] R Chicoisne, D Espinoza, M Goycoolea, E Moreno, and E Rubio. A New Algorithm for the Open-Pit Mine Production Scheduling Problem. Operations Research, 60(3):517-528, 2012. .

[50] C. Cullenbine, R.K. Wood, and A. Newman. A sliding time window heuristic for open pit mine block sequencing. Optimization Letters, 5(3):365-377, 2011. .

[51] H Eivazy and H Askari-Nasab. A mixed integer linear programming model for short-term open pit mine production scheduling. Mining Technology, 121(2):97-108, 2012. .

[52] M E Gershon. Optimal mine production scheduling: evaluation of large scale mathematical programming approaches. International Journal of Mining Engineering, 1(4):315-329, 1983.

[53] T B Johnson. Optimum open pit mine production scheduling. PhD thesis, CALIFORNIA UNIV BERKELEY OPERATIONS RESEARCH CENTER, Berkeley, California, USA, 1968.

[54] A Kumar and S Chatterjee. Open-pit coal mine production sequencing incorporating grade blending and stockpiling options: An application from an Indian mine. Engineering Optimization, 49(5):762776, 2017. . URL https://doi .org/10.1080/0305215X.2016.1210312.

[55] E. Moreno, M. Rezakhah, A. Newman, and F. Ferreira. Linear models for stockpiling in openpit mine production scheduling problems. European Journal of Operational Research, 260(1):212221, 2017. ISSN 0377-2217. . URL http://www.sciencedirect.com/science/article/pii/ S0377221716310335.

[56] Y Pourrahimian, H Askari-Nasab, and D D Tannant. A multi-step approach for block-cave production scheduling optimization. International Journal of Mining Science and Technology, 23(5):739-750, 2013. ISSN 2095-2686.

[57] B Samanta, A Bhattacherjee, and R Ganguli. A genetic algorithms approach for grade control planning in a bauxite deposit. In Proceedings of the 32nd International Symposium on Applications of Computers and Operations Research in the Mineral Industry, pages 337-342, 2005.

[58] B Tolwinski and R Underwood. A scheduling algorithm for open pit mines. IMA Journal of Management Mathematics, 7(3):247-270, 1996.

[59] A Weintraub, M Pereira, and X Schultz. A Priori and A Posteriori Aggregation Procedures to Reduce Model Size in MIP Mine Planning Models. Electronic Notes in Discrete Mathematics, 30(Supplement C):297-302, 2008. ISSN 1571-0653.

[60] Y. Li, E. Topal, and S. Ramazan. Optimising the long-term mine waste management and truck schedule in a large-scale open pit mine. Mining Technology, 125(1):35-46, 1 2016. ISSN 1474-9009. .

[61] Y. Li, E. Topal, and S. Ramazan. Optimising the Long Term Mine Landform Progression and Truck 
Hour Schedule in a Large Scale Open Pit Mine Using Mixed Integer Programming. In Roussos Dimitrakopoulos, editor, Advances in Applied Strategic Mine Planning, pages 669-686. Springer International Publishing, Cham, 2018. ISBN 978-3-319-69320-0. .

[62] K. Fytas, J. Hadjigeorgiou, and J. L. Collins. Production scheduling optimization in open pit mines. International Journal of Surface Mining, Reclamation and Environment, 7(1):1-9, 1 1993. ISSN 13895265. . URL http://www.tandfonline.com/doi/abs/10.1080/09208119308964677.

[63] W.M. Carlyle and B.C. Eaves. Underground Planning at Stillwater Mining Company. Interfaces, 31 (4):50-60, 8 2001. ISSN 0092-2102. .

[64] M. Nehring, E. Topal, M. Kizil, and P. Knights. An investigation to integrate optimum long-term planning with short planning in underground mine production scheduling. In Mine Planning and Equipment Selection (MPES) Conference / Fremantle, WA, 2010.

[65] M. Nehring, E. Topal, M. Kizil, and P. Knights. Integrated short- and medium-term underground mine production scheduling. Journal of the Southern African Institute of Mining and Metallurgy, 112: 365-378, 2012. ISSN 2225-6253.

[66] S.C. Sarin and J. West-Hansen. The long-term mine production scheduling problem. IIE Transactions, 37(2):109-121, 2 2005. ISSN 0740-817X. .

[67] A.M. Newman and M. Kuchta. Using aggregation to optimize long-term production planning at an underground mine. European Journal of Operational Research, 176(2):1205-1218, 12007. ISSN 0377-2217.

[68] E. Topal. Early start and late start algorithms to improve the solution time for long-term underground mine production scheduling. Journal of the Southern African Institute of Mining and Metallurgy, 108: 99-107, 2008. ISSN 2225-6253.

[69] M. Nehring, E. Topal, and J. Little. A new mathematical programming model for production schedule optimization in underground mining operations. Journal of the Southern African Institute of Mining and Metallurgy, 110:437-446, 2010. ISSN 2225-6253.

[70] J Benndorf. Application of efficient methods of conditional simulation for optimising coal blending strategies in large continuous open pit mining operations. International Journal of Coal Geology, 112: 141-153, 2013. ISSN 0166-5162. . URL http://www.sciencedirect.com/science/article/pii/ S0166516212002492.

[71] P Bodon, C Fricke, T Sandeman, and C Stanford. Modeling the mining supply chain from mine to port: A combined optimization and simulation approach. Journal of Mining Science, 47(2):202-211, 2011.

[72] N Boland, I Dumitrescu, and G Froyland. A multistage stochastic programming approach to open pit mine production scheduling with uncertain geology. Optimization Online, 2008.

[73] R. Goodfellow and R. Dimitrakopoulos. Simultaneous Stochastic Optimization of Mining Complexes and Mineral Value Chains. Mathematical Geosciences, 49(3):341-360, 2017. ISSN 1874-8953. . URL https://doi.org/10.1007/s11004-017-9680-3.

[74] R A Halatchev. A model of discounted profit variation of open pit production sequencing optimization. In Application of Computers and Operations Research in the Mineral Industry-Proc. of the 32nd Int. Symposium on the Application of Computers and Operations Research in the Mineral Industry, APCOM 2005, pages 315-323. AA Balkema Publishers, 2005.

[75] B Koushavand, H Askari-Nasab, and C V Deutsch. A linear programming model for long-term mine planning in the presence of grade uncertainty and a stockpile. International Journal of Mining Science and Technology, 24(4):451-459, 2014. ISSN 2095-2686.

[76] A. Lamghari and R. Dimitrakopoulos. A diversified Tabu search approach for the open-pit mine production scheduling problem with metal uncertainty. European Journal of Operational Research, 222(3):642-652, 2012. ISSN 0377-2217. .

[77] A. Lamghari, R. Dimitrakopoulos, and J.A. Ferland. A variable neighbourhood descent algorithm for the open-pit mine production scheduling problem with metal uncertainty. Journal of the Operational Research Society, 65(9):1305-1314, 2014. ISSN 1476-9360. .

[78] M.E.V. Matamoros and R. Dimitrakopoulos. Stochastic short-term mine production schedule accounting for fleet allocation, operational considerations and blending restrictions. European Journal of Operational Research, 255(3):911-921, 2016. ISSN 0377-2217. . URL http: //www . sciencedirect. com/science/article/pii/S0377221716303873.

[79] L. Montiel and R. Dimitrakopoulos. Optimizing mining complexes with multiple processing and trans- 
portation alternatives: An uncertainty-based approach. European Journal of Operational Research, 247 (1):166-178, 2015. ISSN 0377-2217. . URL http://www.sciencedirect.com/science/article/pii/ S0377221715003720.

[80] L. Montiel and R. Dimitrakopoulos. A heuristic approach for the stochastic optimization of mine production schedules. Journal of Heuristics, 23(5):397-415, 2017. ISSN 1572-9397. .

[81] S. Ramazan and R. Dimitrakopoulos. Traditional and New MIP Models for Production Scheduling With In-Situ Grade Variability. International Journal of Surface Mining, Reclamation and Environment, 18(2):85-98, 2004.

[82] S. Gilani and J. Sattarvand. Integrating geological uncertainty in long-term open pit mine production planning by ant colony optimization. Computers \& Geosciences, 87:31-40, 2 2016. ISSN 0098-3004. .

[83] N.L. Mai, E. Topal, O. Erten, and B. Sommerville. A new risk-based optimisation method for the iron ore production scheduling using stochastic integer programming. Resources Policy, 11 2018. ISSN 03014207. . URL https://www.sciencedirect.com/science/article/abs/pii/S0301420717302763.

[84] A. Lamghari and R. Dimitrakopoulos. Network-flow based algorithms for scheduling production in multi-processor open-pit mines accounting for metal uncertainty. European Journal of Operational Research, 250(1):273-290, 4 2016. ISSN 0377-2217.

[85] A. Lamghari and R. Dimitrakopoulos. Progressive hedging applied as a metaheuristic to schedule production in open-pit mines accounting for reserve uncertainty. European Journal of Operational Research , 253(3):843-855, 9 2016. ISSN 0377-2217. . URL https://www.sciencedirect.com/science/ article/pii/S0377221716301357.

[86] I. Inthavongsa, C. Drebenstedt, J. Bongaerts, and P. Sontamino. Real options decision framework: Strategic operating policies for open pit mine planning. Resources Policy, 47:142-153, 3 2016. ISSN 0301-4207. . URL https://www.sciencedirect.com/science/article/abs/pii/ S0301420716300022.

[87] L. Montiel, R. Dimitrakopoulos, and K. Kawahata. Globally optimising open-pit and underground mining operations under geological uncertainty. Mining Technology, 125(1):2-14, 1 2016. ISSN 14749009.

[88] R.C. Goodfellow and R. Dimitrakopoulos. Global optimization of open pit mining complexes with uncertainty. Applied Soft Computing, 40:292-304, 3 2016. ISSN 1568-4946. . URL https://www. sciencedirect.com/science/article/pii/S1568494615007565.

[89] S Alarie and M Gamache. Overview of Solution Strategies Used in Truck Dispatching Systems for Open Pit Mines. International Journal of Surface Mining, Reclamation and Environment, 16(1):59-76, 2002. . URL https://www.tandfonline.com/doi/abs/10.1076/ijsm.16.1.59.3408.

[90] C.N. Burt and L. Caccetta. Equipment Selection for Surface Mining: A Review. Interfaces, 44(2): 143-162, 2014. . URL https://doi.org/10.1287/inte.2013.0732.

[91] M Munirathinam and J C Yingling. A review of computer-based truck dispatching strategies for surface mining operations. International Journal of Surface Mining, Reclamation and Environment, 8(1):1-15, 1994. . URL https://doi.org/10.1080/09208119408964750.

[92] M. Nehring, E. Topal, and P. Knights. Dynamic short term production scheduling and machine allocation in underground mining using mathematical programming. Mining Technology, 119(4):212220, 12 2010. ISSN 1474-9009.

[93] M Gamache, R Grimard, and P Cohen. A shortest-path algorithm for solving the fleet management problem in underground mines. European Journal of Operational Research, 166(2):497-506, 2005. ISSN 0377-2217. . URL http://www.sciencedirect.com/science/article/pii/S037722170400222X.

[94] S Naoum and A Haidar. A hybrid knowledge base system and genetic algorithms for equipment selection. Engineering Construction and Architectural Management, 7(1):3-14, 2000.

[95] S.R. Patterson, E. Kozan, and P. Hyland. Energy efficient scheduling of open-pit coal mine trucks. European Journal of Operational Research, 262(2):759-770, 2017. ISSN 0377-2217. . URL http: //www.sciencedirect.com/science/article/pii/S0377221717303132.

[96] G Singh, D Sier, A T Ernst, O Gavriliouk, R Oyston, T Giles, and P Welgama. A mixed integer programming model for long term capacity expansion planning: A case study from The Hunter Valley Coal Chain. European Journal of Operational Research, 220(1):210-224, 2012. ISSN 0377-2217. . URL http://www.sciencedirect.com/science/article/pii/S0377221712000318.

[97] F Soumis, J Ethier, and J Elbrond. Truck dispatching in an open pit mine. International Journal of Surface Mining, Reclamation and Environment, 3(2):115-119, 1989. . 
[98] N Vagenas. Dispatch control of a fleet of remote-controlled/automatic load-haul-dump vehicles in underground mines. International Journal of Production Research, 29(11):2347-2363, 1991. . URL https://doi.org/10.1080/00207549108948087.

[99] E. Topal and S. Ramazan. A new MIP model for mine equipment scheduling by minimizing maintenance cost. European Journal of Operational Research, 207(2):1065-1071, 12 2010. ISSN 0377-2217.

[100] X. Gu, Q. Wang, X. Xu, J. Liu, T. Sun, and K. Du. Open pit waste removal optimization through equipment fleet scheduling. Transactions of Nonferrous Metals Society of China, 27(12):2682-2690, 12 2017. ISSN 1003-6326. .

[101] M. Beaulieu and M. Gamache. An enumeration algorithm for solving the fleet management problem in underground mines. Computers \& Operations Research, 33(6):1606-1624, 6 2006. ISSN 0305-0548.

[102] E. Bakhtavar and H. Mahmoudi. Development of a scenario-based robust model for the optimal truckshovel allocation in open-pit mining. Computers \&3 Operations Research, 8 2018. ISSN 0305-0548. .

[103] S.R. Dindarloo, M. Osanloo, and S. Frimpong. A stochastic simulation framework for truck and shovel selection and sizing in open pit mines. Journal of the Southern African Institute of Mining and Metallurgy, 115:209-219, 2015. ISSN 2225-6253.

[104] C. H. Ta, J. V. Kresta, J. F. Forbes, and H. J. Marquez. A stochastic optimization approach to mine truck allocation. International Journal of Surface Mining, Reclamation and Environment, 19 (3):162-175, 9 2005. ISSN 1389-5265. . URL http://www.tandfonline.com/doi/abs/10.1080/ 13895260500128914.

[105] S.G. Ercelebi and A. Bascetin. Optimization of shovel-truck system for surface mining. Journal of the Southern African Institute of Mining and Metallurgy, 109:433-439, 2009. ISSN 2225-6253.

[106] C.H. Ta, A. Ingolfsson, and J. Doucette. A linear model for surface mining haul truck allocation incorporating shovel idle probabilities. European Journal of Operational Research, 231(3):770-778, 12 2013. ISSN 0377-2217. .

[107] E. Topal and S. Ramazan. Mining truck scheduling with stochastic maintenance cost. Journal of Coal Science and Engineering (China), 18(3):313-319, 2012. ISSN 1866-6566. .

[108] S. Chopra and P. Meindl. Supply Chain Management Strategy, Planning, and Operation. Pearson Education Limited, Edingurgh Gate, sixth edit edition, 2016.

[109] E. Kozan and S.Q. Liu. A demand-responsive decision support system for coal transportation. Decision Support Systems, 54(1):665-680, 2012. ISSN 0167-9236. . URL http://www.sciencedirect.com/ science/article/pii/S0167923612002278.

[110] R Laurich and B Kennedy. Planning and design of surface mines. In B A Kennedy, editor, Surface Mining, chapter 5.2, pages 465-469. Port City Press,, Baltimore, 1990.

[111] J C Picard. Maximal Closure of a Graph and Applications to Combinatorial Problems. Management Science, 22(11):1268-1272, 1976. . URL https://doi.org/10.1287/mnsc.22.11.1268.

[112] B W Patty. Handbook of Operations Research Applications at Railroads, volume 222. Springer, 2015.

[113] A Abdekhodaee, S Dunstall, A Ernst, and L Lam. Integration of stockyard and rail network: a scheduling case study. In Proceedings of the Fifth Asia Pacific Industrial Engineering and Management Systems Conference, 2004.

[114] A L M Barros. Modelo de Otimização para Distribuição Horária de Lotes de Vagões Ferroviários GDE para Carregamento de Minério de Ferro. PhD thesis, Universidade Federal do Esp $\{\backslash \backslash$ i $\}$ rito Santo, 2010.

[115] N L Boland and M W P Savelsbergh. Optimizing the Hunter Valley Coal Chain. In H Gurnani, A Mehrotra, and S Ray, editors, Supply Chain Disruptions: Theory and Practice of Managing Risk, pages 275-302. Springer London, London, 2012. ISBN 978-0-85729-778-5. . URL https://doi.org/ 10.1007/978-0-85729-778-5_10.

[116] L B Campos. Modelo de otimização para o planejamento da rede de serviços no transporte ferroviário de cargas. PhD thesis, Universidade Federal do Esp $\{\backslash \backslash \backslash$ i $\}$ rito Santo, 2009.

[117] L.B. Campos, M.M. da Costa Cruz, and F.M. Pompermayer. Modelo integrado de apoio ao planejamento da rede de serviços no transporte ferroviário de cargas: aplicação para transporte de minério de ferro. TRANSPORTES, 18(2), 2010.

[118] R Garcia-Flores, G Singh, A Ernst, and P Welgama. Medium-term rail planning at Rio Tinto Iron Ore. In Proceedings of the 19th International Congress on Modelling and Simulation (MODSIM 2011), 
pages 311-317. Modelling and Simulation Society of Australia and New Zealand (MSSANZ), 2011.

[119] I E Içyüz, J P P Richard, E Eskigun, and D Acharya. A Two-Model Solution Approach for the Monthly Coal Train Reservations Planning Problem. Transportation Science, 50(3):926-946, 2016. URL https://doi.org/10.1287/trsc.2015.0654.

[120] S.Q. Liu and E. Kozan. Scheduling trains as a blocking parallel-machine job shop scheduling problem. Computers $\& 3$ Operations Research, 36(10):2840-2852, 2009. ISSN 0305-0548. . URL http://www. sciencedirect.com/science/article/pii/S0305054808002712.

[121] S.Q. Liu and E. Kozan. Optimizing a coal rail network under capacity constraints. Flexible Services and Manufacturing Journal, 23(2):90-110, 6 2011. ISSN 1936-6590. . URL https://doi.org/10. 1007/s10696-010-9069-9.

[122] M. Masoud, E. Kozan, G. Kent, and S.Q. Liu. A new constraint programming approach for optimising a coal rail system. Optimization Letters, 11(4):725-738, 2017. ISSN 1862-4480. . URL https: //doi.org/10.1007/s11590-016-1041-5.

[123] M A Nobrega. Modelagem matematica de um sistema de produção e transporte de minerio de ferro. PhD thesis, UNIVERSIDADE ESTADUAL DE CAMPINAS, Campinas, SP, Brasil, 1997.

[124] V Salim and X Cai. A genetic algorithm for railway scheduling with environmental considerations. Environmental Modelling \& Software, 12(4):301-309, 1997. ISSN 1364-8152. . URL http://www. sciencedirect.com/science/article/pii/S1364815297000261.

[125] G Singh, A T Ernst, M Baxter, and D Sier. Rail schedule optimisation in the hunter valley coal chain. RAIRO-Oper. Res., 49(2):413-434, 2015. . URL https://doi.org/10.1051/ro/2014049.

[126] G Singh, R García-Flores, A Ernst, P Welgama, M Zhang, and K Munday. Medium-Term Rail Scheduling for an Iron Ore Mining Company. Interfaces, 44(2):222-240, 2014. . URL https://doi . org/10.1287/inte.1120.0669.

[127] A Thomas, M Krishnamoorthy, J Venkateswaran, and G Singh. Decentralised decision-making in a multi-party supply chain. International Journal of Production Research, 54(2):405-425, 2016. . URL https://doi.org/10.1080/00207543.2015.1096977.

[128] A Thomas, G Singh, M Krishnamoorthy, and J Venkateswaran. Distributed optimisation method for multi-resource constrained scheduling in coal supply chains. International Journal of Production Research, 51(9):2740-2759, 2013. . URL http://dx.doi.org/10.1080/00207543.2012.737955.

[129] A Thomas, J Venkateswaran, G Singh, and M Krishnamoorthy. A resource constrained scheduling problem with multiple independent producers and a single linking constraint: A coal supply chain example. European Journal of Operational Research, 236(3):946-956, 2014. ISSN 0377-2217. . URL http://www.sciencedirect.com/science/article/pii/S0377221713008084.

[130] J. Balzary and A. Mohais. Consideration for Multi-objective Metaheuristic Optimisation of Large Iron Ore and Coal Supply Chains, from Resource to Market. In R Dimitrakopoulos, editor, Advances in Applied Strategic Mine Planning, pages 297-316. Springer International Publishing, Cham, 2018. ISBN 978-3-319-69320-0. . URL https://doi .org/10.1007/978-3-319-69320-0_20.

[131] C.H.F. de Faria and M.M. da Costa Cruz. Simulation Modelling of Vitória-Minas Closed-Loop Rail Network. Transport Problems, 10(SE):125-139, 2015.

[132] R P L Meireles. Modelagem e Simulação da Malha Ferroviária em Circuito Fechado da Estrada de Ferro de Vitória a Minas. PhD thesis, Universidade Federal do Esp $\{\backslash \backslash \backslash \mathrm{i}\}$ rito Santo, 2010.

[133] G Reinhardt, M Dada, and S Chopra. Coal Movement by Railroad in the Powder River Basin. Energy Studies Review, 11(1), 2002.

[134] M Ago, T Nishi, and M Konishi. Simultaneous Optimization of Storage Allocation and Routing Problems for Belt-conveyor Transportation. Journal of Advanced Mechanical Design, Systems, and Manufacturing, 1(2):250-261, 2007. .

[135] G Belov, N Boland, M W P Savelsbergh, and P J Stuckey. Local Search for a Cargo Assembly Planning Problem. In H Simonis, editor, Integration of AI and OR Techniques in Constraint Programming, pages 159-175, Cham, 2014. Springer International Publishing. ISBN 978-3-319-07046-9.

[136] G Belov, N Boland, M W P Savelsbergh, and P J Stuckey. Exploration of models for a cargo assembly planning problem. ArXiv e-prints, 2015.

[137] N Boland, D Gulczynski, and M Savelsbergh. A stockyard planning problem. EURO Journal on Transportation and Logistics, 1(3):197-236, 2012. ISSN 2192-4384. . URL https://doi.org/10. 1007/s13676-012-0011-z.

[138] N Boland, D Gulezynski, M P Jackson, M Savelsbergh, and M K Tam. Improved stockyard man- 
agement strategies for coal export terminal at Newcastle. In Proceedings of the 19th International Congress on Modelling and Simulation (Perth, W.A. 12-16 December, 2011), pages 718-724, 2011.

[139] S Hanoun, B Khan, M Johnstone, S Nahavandi, and D Creighton. An effective heuristic for stockyard planning and machinery scheduling at a coal handling facility. In Industrial Informatics (INDIN), 2013 11th IEEE International Conference on, pages 206-211. IEEE, 2013.

[140] M Savelsbergh and O Smith. Cargo assembly planning. EURO Journal on Transportation and Logistics, 4(3):321-354, 2015. ISSN 2192-4384. . URL https://doi.org/10.1007/s13676-014-0048-2.

[141] M Binkowski and B J McCarragher. A Queueing Model for the Design and Analysis of a Mining Stockyard. Discrete Event Dynamic Systems, 9(1):75-98, 1 1999. ISSN 1573-7594. . URL https: //doi.org/10.1023/A:1008397332376.

[142] V T Le, M Johnstone, J Zhang, B Khan, D Creighton, S Hanoun, and S Nahavandi. Complex Simulation of Stockyard Mining Operations. In D Gao, N Ruan, and W Xing, editors, Advances in Global Optimization, pages 529-537, Cham, 2015. Springer International Publishing. ISBN 978-3-31908377-3.

[143] M M Fioroni, L A G Franzese, C E Zanin, J Furia, L de Toledo Perfetti, D Leonardo, and N L da Silva. Simulation of continuous behavior using discrete tools: Ore conveyor transport. In 2007 Winter Simulation Conference, pages 1655-1662, 2007.

[144] S Que, K Awuah-Offei, and S Frimpong. Optimising design parameters of continuous mining transport systems using discrete event simulation. International Journal of Mining, Reclamation and Environment, 30(3):217-230, 2016. . URL https://doi.org/10.1080/17480930.2015.1037056.

[145] T van Vianen, J Ottjes, and G Lodewijks. Belt conveyor network design using simulation. Journal of Simulation, 10(3):157-165, 2016. . URL https://doi.org/10.1057/jos. 2014.38.

[146] B Xiao-Ping, Z A Yu-Hong, and L A Ya-Nan. A Novel Approach to Study Real-Time Dynamic Optimization Analysis and Simulation of Complex Mine Logistics Transportation Hybrid System with Belt and Surge Links. Discrete Dynamics in Nature and Society, 2015:1-8, 2015.

[147] R.L. McNearny and Z. Nie. Simulation of a conveyor belt network at an underground coal mine. Mineral Resources Engineering, 09(03):343-355, 2000. .

[148] K Fagerholt. Optimal fleet design in a ship routing problem. International Transactions in Operational Research, 6(5):453-464, 1999. ISSN 0969-6016. . URL http://www.sciencedirect.com/science/ article/pii/S0969601699000106.

[149] M Christiansen, K Fagerholt, B Nygreen, and D Ronen. Ship routing and scheduling in the new millennium. European Journal of Operational Research, 228(3):467-483, 2013. ISSN 0377-2217. URL http://www.sciencedirect.com/science/article/pii/S0377221712009125.

[150] M Christiansen, K Fagerholt, and D Ronen. Ship Routing and Scheduling: Status and Perspectives. Transportation Science, 38(1):1-18, 2004. . URL https://pubsonline.informs.org/doi/abs/10. $1287 / \operatorname{trsc} .1030 .0036$.

[151] D Steenken and S Voßand R Stahlbock. Container terminal operation and operations research - a classification and literature review. OR Spectrum, 26(1):3-49, 1 2004. ISSN 1436-6304. . URL https://doi .org/10.1007/s00291-003-0157-z.

[152] R Stahlbock and S Voß. Operations research at container terminals: a literature update. OR Spectrum, 30(1):1-52, 1 2008. ISSN 1436-6304. . URL https://doi.org/10.1007/s00291-007-0100-9.

[153] A. Arigoni, A. Newman, C. Turner, and C. Kaptur. Optimizing global thermal coal shipments. Omega, 72(Supplement C):118-127, 2017. ISSN 0305-0483. . URL http://www.sciencedirect. com/science/article/pii/S0305048316300792.

[154] M Christiansen, K Fagerholt, T Flatberg, Ø Haugen, O Kloster, and E H Lund. Maritime inventory routing with multiple products: A case study from the cement industry. European Journal of Operational Research, 208(1):86-94, 2011. ISSN 0377-2217. . URL http://www.sciencedirect.com/ science/article/pii/S0377221710005606.

[155] C M Liu. A Blending and Inter-Modal Transportation Model for the Coal Distribution Problem. International Journal of Operations Research, 5(2):107-116, 2008.

[156] L H Shih. Planning of fuel coal imports using a mixed integer programming method. International Journal of Production Economics, 51(3):243-249, 1997. ISSN 0925-5273. . URL http: //www.sciencedirect.com/science/article/pii/S0925527397000789.

[157] Q Zeng and Z Yang. Model Integrating Fleet Design and Ship Routing Problems for Coal Shipping. In Y Shi, G D van Albada, J Dongarra, and P M A Sloot, editors, Computational Science - ICCS 
200\%: 7th International Conference, Beijing, China, May 27-30, 2007, Proceedings, Part III, pages 1000-1003, Berlin, Heidelberg, 2007. Springer Berlin Heidelberg. ISBN 978-3-540-72588-6. .

[158] J Dong, F Gao, S Dai, X Guan, R Ma, and F Lai. Purchasing and transport scheduling based on scenario tree in coal maritime supply chain with stochastic demand. In Proceeding of the 11th World Congress on Intelligent Control and Automation, pages 3444-3449, 2014. .

[159] R Barbaro and R Ramani. Generalized multiperiod MIP model for production scheduling and processing facilities selection and location. Mining Engineering, 38(2):107-114, 1986.

[160] P Benalcazar, J Kamiński, and P Saługa. The storage location problem in a coal supply chain: background and methodological approach. Gospodarka Surowcami Mineralnymi, 33(1):5-14, 2017. ISSN 2299-2324. . URL https://doi .org/10.1515/gospo-2017-0009.

[161] L Canales-Bustos, E Santibañez-González, and A Candia-Véjar. A multi-objective optimization model for the design of an effective decarbonized supply chain in mining. International Journal of Production Economics, 193:449-464, 2017. ISSN 0925-5273. . URL http://www.sciencedirect.com/science/ article/pii/S0925527317302542.

[162] M Chakraborty and M K Chandra. Multicriteria decision making for optimal blending for beneficiation of coal: a fuzzy programming approach. Omega, 33(5):413-418, 2005. ISSN 0305-0483. . URL http://www.sciencedirect.com/science/article/pii/S0305048304001008.

[163] E K C Chanda and K Dagdelen. Optimal blending of mine production using goal programming and interactive graphics systems. International Journal of Surface Mining, Reclamation and Environment, 9(4):203-208, 1995. . URL https://doi.org/10.1080/09208119508964748.

[164] J M Henderson. A Short-Run Model for the Coal Industry. The Review of Economics and Statistics, 37(4):336-346, 1955. ISSN 00346535, 15309142. URL http://www.jstor.org/stable/1925847.

[165] J M Henderson. The Efficiency of the Coal Industry-An Application of Linear Programming. PhD thesis, Harvard University Press, Cambridge, Mass., 1958.

[166] J W Lai and C Y Chen. A cost minimization model for coal import strategy. Energy Policy, 24(12): 1111-1117, 1996. ISSN 0301-4215. . URL http://www.sciencedirect.com/science/article/pii/ S0301421596000912.

[167] Y F Liao, C H Wu, and X Q Ma. New hybrid optimization model for power coal blending. In Machine Learning and Cybernetics, 2005. Proceedings of 2005 International Conference on, volume 7, pages 4023-4027. IEEE, 2005.

[168] C M Liu and H D Sherali. A coal shipping and blending problem for an electric utility company. Omega, 28(4):433-444, 2000. ISSN 0305-0483. . URL http://www.sciencedirect.com/science/ article/pii/S0305048399000675.

[169] F Liu, T Lv, M Sajid, and X Li. Optimization for China's coal flow based on matching supply and demand sides. Resources, Conservation and Recycling, 129:345-354, 2018. ISSN 0921-3449. . URL http://www.sciencedirect.com/science/article/pii/S0921344916302051.

[170] J Lyu, A Gunasekaran, C Y Chen, and C Kao. A goal programming model for the coal blending problem. Computers $\&$ Industrial Engineering, 28(4):861-868, 1995. ISSN 0360-8352. . URL http: //www.sciencedirect.com/science/article/pii/036083529500007N.

[171] L G Márquez. Optimización de una red de transporte combinado para la exportación del carbón del interior de Colombia. Revista EIA, pages 103-113, 2011. ISSN 1794-1237. URL http://www.scielo. org.co/scielo.php?script=sci_arttext\&pid=S1794-12372011000200008\&nrm=iso.

[172] P C Pendharkar. A fuzzy linear programming model for production planning in coal mines. Computers E Operations Research, 24(12):1141-1149, 1997. ISSN 0305-0548. .

[173] P C Pendharkar and J A Rodger. Nonlinear programming and genetic search application for production scheduling in coal mines. Annals of Operations Research, 95(1):251-267, 1 2000. ISSN 1572-9338. . URL https://doi.org/10.1023/A:1018958209290.

[174] H J Peng, M H Zhou, M Z Liu, Y Zhang, and Y B Huang. A dynamic optimization model of an integrated coal supply chain system and its application. Mining Science and Technology (China), 19(6):842-846, 2009. ISSN 1674-5264. . URL http://www.sciencedirect.com/science/article/ $\mathrm{pii} / \mathrm{S} 1674526409601538$.

[175] M Promban and O Kittithreerapronchai. Robust Optimization for Coal Transportation Planning. Journal of Engineering and Applied Science, 12(1):5609-5616, 2017. ISSN 1816-949X.

[176] A Ravindran and D L Hanline. Optimal Location of Coal Blending Plants by Mixed-Integer Programming. AIIE Transactions, 12(2):179-185, 1980. . URL https://doi.org/10.1080/ 
05695558008974505.

[177] S Schellenberg, X Li, and Z Michalewicz. Benchmarks for the Coal Processing and Blending Problem. In Proceedings of the Genetic and Evolutionary Computation Conference 2016, GECCO '16, pages 1005-1012, New York, NY, USA, 2016. ACM. ISBN 978-1-4503-4206-3. . URL http://doi.acm. org/10.1145/2908812.2908945.

[178] H D Sherali and R Puri. Models for a coal blending and distribution problem. Omega, 21(2): 235-243, 1993. ISSN 0305-0483. . URL http://www.sciencedirect.com/science/article/pii/ 030504839390056Q.

[179] G H Tzeng, D Teodorović, and M J Hwang. Fuzzy bicriteria multi-index transportation problems for coal allocation planning of Taipower. European Journal of Operational Research, 95(1): 62-72, 1996. ISSN 0377-2217. . URL http://www.sciencedirect.com/science/article/pii/ 0377221795002472.

[180] G Xi-Jin, C Ming, and W Jia-Wei. Coal blending optimization of coal preparation production process based on improved GA. Procedia Earth and Planetary Science, 1(1):654-660, 2009. ISSN 1878-5220. . URL http://www.sciencedirect.com/science/article/pii/S1878522009001040.

[181] A Arigoni. Optimization techniques in coal markets : a global cost minimization and a multi-stage procurement strategy. PhD thesis, Colorado School of Mines. Arthur Lakes Library, Golden, Colorado, USA, 2016.

[182] P. Bodon, C. Fricke, T. Sandeman, and C. Stanford. Combining Optimisation and Simulation to Model a Supply Chain from Pit to Port. In R Dimitrakopoulos, editor, Advances in Applied Strategic Mine Planning, pages 251-267. Springer International Publishing, Cham, 2018. ISBN 978-3-319-69320-0. . URL https://doi .org/10.1007/978-3-319-69320-0_17.

[183] W Candler. Coal blending - with acceptance sampling. Computers \& Operations Research, 18(7): 591-596, 1991. ISSN 0305-0548. . URL http://www.sciencedirect.com/science/article/pii/ $030505489190066 Z$.

[184] Q Cheng, S Ning, X Xia, and F Yang. Modelling of coal trade process for the logistics enterprise and its optimisation with stochastic predictive control. International Journal of Production Research, 54 (8):2241-2259, 2016. . URL https://doi.org/10.1080/00207543.2015.1062568.

[185] D G Conradie, L E Morison, and J W Joubert. Scheduling at coal handling facilities using Simulated Annealing. Mathematical Methods of Operations Research, 68(2):277-293, 2008. ISSN 1432-5217. . URL https://doi.org/10.1007/s00186-008-0221-1.

[186] C Dai, X H Cai, Y P Cai, and G H Huang. A simulation-based fuzzy possibilistic programming model for coal blending management with consideration of human health risk under uncertainty. Applied Energy, 133:1-13, 2014. ISSN 0306-2619. . URL http://www.sciencedirect.com/science/article/ $\mathrm{pii/S0306261914007831.}$

[187] M Kumral. Application of chance-constrained programming based on multi-objective simulated annealing to solve a mineral blending problem. Engineering Optimization, 35(6):661-673, 2003. . URL https://doi.org/10.1080/03052150310001614837.

[188] W Li, G H Huang, C Dong, and Y Liu. An Inexact Fuzzy Programming Approach for Power Coal Blending. Journal of Environmental Informatics, 21(2), 2013. ISSN 1684-8799.

[189] Y. Liu, G. H. Huang, Y. P. Cai, G. H. Cheng, Y. T. Niu, and K. An. Development of an inexact optimization model for coupled coal and power management in North China. Energy Policy, 37(11): 4345-4363, 2009. ISSN 0301-4215. . URL http://www.sciencedirect.com/science/article/pii/ S0301421509003942.

[190] B.S. Pimentel, G.R. Mateus, and F.A. Almeida. Stochastic capacity planning and dynamic network design. International Journal of Production Economics, 145(1):139-149, 2013. ISSN 0925-5273. . URL http://www.sciencedirect.com/science/article/pii/S0925527313000376.

[191] Ü S Sakall $\backslash \mathrm{i}$ and Ö F Baykoç. An optimization approach for brass casting blending problem under aletory and epistemic uncertainties. International Journal of Production Economics, 133(2): 708-718, 2011. ISSN 0925-5273. . URL http://www.sciencedirect.com/science/article/pii/ S0925527311002398.

[192] Ü S Sakall \i and Ö F Baykoç. Strong guidance on mitigating the effects of uncertainties in the brass casting blending problem: a hybrid optimization approach. Journal of the Operational Research Society, 64(4):562-576, 2013. ISSN 1476-9360. . URL https://doi.org/10.1057/jors.2012.50.

[193] Ü S Sakall \i, Ö F Baykoç, and B Birgören. Stochastic optimization for blending problem in brass 
casting industry. Annals of Operations Research, 186(1):141-157, 6 2011. ISSN 1572-9338. . URL https://doi.org/10.1007/s10479-011-0851-1.

[194] J S Shih and H C Frey. Coal blending optimization under uncertainty. European Journal of Operational Research, 83(3):452-465, 1995. ISSN 0377-2217. . URL http://www. sciencedirect.com/science/ article/pii/0377221794002436.

[195] J. Zhang and R. Dimitrakopoulos. Optimising a Mineral Supply Chain Under Uncertainty with LongTerm Sales Contracts. In R Dimitrakopoulos, editor, Advances in Applied Strategic Mine Planning, pages 787-800. Springer International Publishing, Cham, 2018. ISBN 978-3-319-69320-0. . URL https://doi.org/10.1007/978-3-319-69320-0_45.

[196] R J Zhou and L J Li. Joint capacity planning and distribution network optimization of coal supply chains under uncertainty. AIChE Journal, 64(4):1246-1261, 2018. . URL https://onlinelibrary. wiley.com/doi/abs/10.1002/aic.16012.

[197] Z. Drezner and H.W. Hamacher, editors. Facility Location: Applications and Theory. Springer, New York, 2004.

[198] Andreas Klose and Andreas Drexl. Facility location models for distribution system design. European Journal of Operational Research, 162(1):4-29, 4 2005. ISSN 0377-2217. . URL https: //www.sciencedirect.com/science/article/abs/pii/S0377221703008191.

[199] M T Melo, S Nickel, and F Saldanha-da Gama. Facility location and supply chain management - A review. European Journal of Operational Research, 196(2):401-412, 2009. ISSN 0377-2217. .

[200] C.S. ReVelle, H.A. Eiselt, and M.S. Daskin. A bibliography for some fundamental problem categories in discrete location science. European Journal of Operational Research, 184(3):817-848, 2 2008. ISSN 0377-2217. . URL https://www.sciencedirect.com/science/article/abs/pii/ S037722170700080X.

[201] M Kumral. Optimal location of a mine facility by genetic algorithms. Mining Technology, 113(2): 83-88, 2004. . URL https://doi.org/10.1179/037178404225004940.

[202] H Luss. Operations Research and Capacity Expansion Problems: A Survey. Operations Research, 30 (5):907-947, 1982. . URL https://doi.org/10.1287/opre.30.5.907. 